
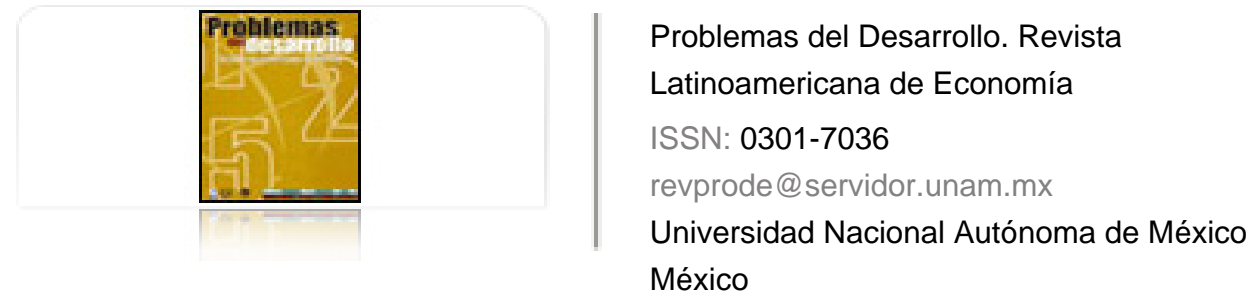

Carmagnani, Marcello

La agricultura familiar en América Latina

Problemas del Desarrollo. Revista Latinoamericana de Economía, vol. 39, núm. 153, abril-junio, 2008,

pp. 11-56

Universidad Nacional Autónoma de México

Distrito Federal, México

Disponible en: http://www.redalyc.org/articulo.oa?id=11820161002

Cómo citar el artículo

- Número completo

- Más información del artículo

Página de la revista en redalyc.org

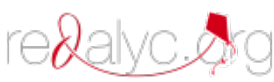

Sistema de Información Científica

Red de Revistas Científicas de América Latina, el Caribe, España y Portugal Proyecto académico sin fines de lucro, desarrollado bajo la iniciativa de acceso abierto 


\title{
LA AGRICULTURA FAMILIAR EN AMÉRICA LATINA
}

\author{
Marcello Carmagnani*
}

Fecha de recepción: 17 de octubre de 2007. Fecha de aceptación: 27 de febrero de 2008.

\section{Resumen}

El trabajo ilustra las características que presenta la agricultura familiar en América Latina tomando en cuenta la dimensión productiva, la complementariedad entre la actividad agrícola y la no agrícola, así como la dotación y distribución de sus activos materiales -económicos y sociales-e inmateriales — políticos y culturales-. El análisis fue posible gracias a un estudio de los censos agropecuarios elaborados por las diferentes institucionales nacionales latinoamericanas en la década de los noventa del siglo anterior y los primeros años de éste. Los censos agropecuarios y los conceptos económicos y sociales permitieron reconstruir la racionalidad que caracteriza la agricultura familiar y, en especial, su estrategia productiva y su capacidad de proyección hacia el mercado.

Palabras claves: agricultura familiar, America Latina, siglo XXI y censos agropecuarios.

* Profesor-investigador del Colegio de México y la Universidad de Turín. Correo electrónico: mcarmag@colmex.mx.

Agradezco a Oficina Regional de la FAO para América Latina y el Caribe que me dio la posibilidad de realizar este estudio; a Alicia Hernández Chávez, profesora de El Colegio de México, por los comentarios al presente estudio y las aportaciones que me ha proporcionado con base en su experiencia del mundo rural mexicano, y a Gustavo Gordillo de Anda, por su apoyo en la realización de la investigación. 


\section{Summary}

The work illustrates the characteristics present in family farming in Latin America, taking into account the productive dimension, complementarity between agricultural and non-agricultural activity, as well as the endowment and distribution of materialeconomic and social -and non-material assets - political and cultural. The analysis was possible thanks to a study of the farm censuses elaborated by various Latin American national institutions in the 1990s and during the first years of this century. The farm censuses and economic and social concepts made it possible to reconstruct the rationale characterizing family farming, and, in particular, its productive strategy and its capacity to serve the market.

Key words: family farming, Latin America, 21st century, farm censuses, productive strategy.

\section{Résumé}

Ce travail illustre les caractéristiques présentées par l'agriculture familiale en Amérique latine, prenant en compte la dimension productive, la complémentarité entre l'activité agricole et la non agricole, ainsi que la dotation et la distribution de leurs actifs matériels - économiques et sociaux - et immatériels - politiques et culturels. L'analyse a été rendue possible par une étude des recensements en matière d'agriculture et d'élevage réalisés par les différentes institutions nationales latino-américaines dans les années 90 du siècle dernier et les premières années de celui-ci. Ces recensements et les concepts économiques et sociaux ont permis de reconstruire la rationalité qui caractérise l'agriculture familiale et notamment sa stratégie productive et sa capacité de projection vers le marché.

Mots clés: agriculture familiale, Amérique latine, XXIe siècle, recensements en matière d'agriculture et d'élevage, stratégie productive.

\section{Resumo}

O trabalho ilustra as características que apresenta a agricultura familiar na América Latina tomando em conta a dimensão produtiva, a complementaridade entre a atividade agrícola e a não agrícola, bem como a dotação e distribuição de seus ativos materiais - econômicos e sociais - e imateriais - políticos e culturais. A análise foi possível graças a um estudo dos censos agropecuários elaborados pelas diferentes instituições nacionais latino-americanas nos anos noventa do século anterior e os primeiros anos deste. Os censos agropecuários e os conceitos econômicos e sociais permitiram reconstruir a racionalidade que caracteriza a agricultura familiar e, em especial, sua estratégia produtiva e sua capacidade de projeção em relação ao mercado.

Palavras-chave: agricultura familiar, América Latina, século XXI, censos agropecuários e estratégia produtiva. 


\section{Introducción}

1 presente estudio se centra en la agricultura familiar y cuestiona su imagen
tradicional fundada en la tipología de las formas agropecuarias, que toma en
cuenta esencialmente la dualidad o bimodalidad de agricultura familiar-agricultura empresarial y no da la debida importancia a la complementariedad existente en el mundo rural entre la actividad agrícola y la no agrícola.

El análisis se basa en la comparación de los censos agropecuarios elaborados en la década de los noventa del siglo anterior con los primeros años de éste, además de tomar en consideración los múltiples trabajos relativos al tema, con el fin de construir una categoría de agricultura familiar que dé la debida importancia a los actores sociales, a la familia de agricultores y a la dotación y distribución, o adjudicación de sus activos materiales o tangibles, e inmateriales o intangibles disponibles.

Analizaré los problemas acerca de si la agricultura familiar es una categoría con la misma racionalidad que las otras formas de agricultura. Ello significa interrogarse sobre la posibilidad de elaborar una caracterización de la agricultura familiar a partir de activos tangibles e intangibles a disposición de los miembros del núcleo familiar, sobre las decisiones que adoptan las familias para definir sus estrategias productivas y sobre el vínculo permanente de las unidades productivas con el mercado y los servicios públicos y privados.

\section{Caracterizaciones de la agricultura familiar}

La categoría de agricultura familiar ha sido objeto de múltiples definiciones que sólo confunden el concepto. Su caracterización principal deriva esencialmente del sistema de la tipología. La tipología es un sistema lógico que busca mostrar el conjunto —en este caso la agricultura— mediante una repartición del universo —en este caso el universo rural - entre diferentes formas de agricultura y actividades. Lo logra a partir de la identificación de un grupo de personas, familias o unidades productivas al cual no se le atribuye ningún valor o valor cero (por ejemplo, los agricultores sin tierras) y luego procede a organizar los grupos subsecuentes con elementos comunes (por ejemplo, la tenencia de la tierra), según un número natural mayor de cero.

La aproximación tipológica es empleada en todos los estudios realizados por el Comité Interamericano de Desarrollo Agrícola (CIDA). Este organismo se creó en la Conferencia Interamericana de Punta del Este de 1959 con el fin de impulsar progra- 
mas de reforma agraria; de este comité nace la primera caracterización de agricultura familiar (Barraclough y Collarte, 1971).

El CIDA escogió el sistema de tipología porque le ofrecía la posibilidad "de reducir al mínimo la dificultad de diferenciar la tenencia de la tierra para estudiar las relaciones entre tenencia de la tierra y desarrollo" y, en especial, abordar "un análisis más detallado de la organización y de las relaciones de la tenencia dentro de las fincas individuales, y el marco institucional de los derechos de propiedad, gobierno, mercados, crédito, etcétera". Se introdujo así "un concepto de tamaño basado en la extensión indispensable para proporcionar empleo remunerado a una familia campesina típica, utilizando los recursos técnicos con que se cuenta en la región y de acuerdo con los valores culturales locales" (Barraclough y Collarte, 1972:13-14).

Como puede observarse, el valor cero de la tipología es el predio de tamaño subfamiliar, o sea la unidad productiva cuyas tierras son insuficientes para satisfacer las necesidades mínimas de una familia. La forma de agricultura siguiente es la familiar, definida como la unidad productiva "cuyas tierras son suficientes para proporcionar sustento a una familia (con una fuerza laboral equivalente a un número de dos a cuatro hombres), un nivel de vida satisfactorio, mediante el trabajo de sus miembros y la aplicación de la técnica predominante en la región". La tipología identifica en seguida la agricultura "multifamiliar de tamaño medio", que conjuga la mano de obra familiar con la contratada, y la agricultura "multifamiliar de gran tamaño", que emplea más de 12 hombres y que requiere, por tanto, una "división del trabajo y el establecimiento de una jerarquía administrativa (Barraclough y Collarte, 1972:14-15).

El uso de esta tipología en los informes nacionales conduce a que la tenencia de la tierra ocupe una posición central. Por tenencia de la tierra se entiende "un sistema de relaciones sociales y económicas, factor crucial para perpetuar el círculo de la pobreza rural y de la baja productividad" porque "el control sobre la tierra determina en gran parte la distribución de la riqueza en las zonas agrícolas atrasadas técnicamente". El resultado es que "las relaciones de tenencia de la tierra tienden a coincidir con las relaciones de poder". Estas últimas son el producto de las "modalidades tradicionales de la tenencia de la tierra" como de la concentración de la tierra en pocas manos. Sin embargo, esta estructura de dominación se puede modificar mediante la reforma agraria que cambia y transforma las relaciones de poder en el agro dando vida a un nuevo sistema de tenencia que puede ser cooperativo, comunal, corporativo, aunque "el sistema de tenencia modelo que los reformistas proponen con mayor frecuencia es la propiedad familiar operada por el propietario" (Barraclough y Collarte, 1972:41-50 y 105-106). 
La tipología de un mundo rural que va desde la agricultura "subfamiliar" a la "multifamiliar de gran tamaño" fue sólo parcialmente afectada por la difusión —en las décadas de los setenta y ochenta - de una nueva categoría, la de "economía campesina". La tipología por predios y dicha categoría se adoptaron por la sociología en la medida que facilitaron la identificación de la agricultura campesina con la agricultura familiar, sin ser sinónimos predios y economía campesina, desde un punto de vista objetivo.

La economía campesina es una "forma sui generis de organización de la producción, es el sector de la actividad agropecuaria nacional donde el proceso productivo es desarrollado por unidades de tipo familiar con el objeto de asegurar, ciclo a ciclo, la reproducción de sus condiciones de vida y trabajo". La economía campesina en cuanto agricultura familiar es simultáneamente una unidad de producción y de consumo, unidad que logra con la intensidad del trabajo y participa parcialmente en el mercado (Schejtman, 1975).

La identificación de la economía campesina con la agricultura familiar no favoreció una mejor comprensión de la lógica productiva familiar y su capacidad de vincularse con la economía real y financiera. Por el contrario, aumentó el nominalismo de la tipología, pues terminó por multiplicar las virtuales formas de la agricultura. Se construyó incluso una subtipología reservada a la economía campesina que pretende distinguir otras cuatro formas: infrasubsistencia, subsistencia, estacionaria y excedentaria. El resultado fue que de las cuatro formas de agricultura iniciales, se pasó a ocho (CEPAL, 1982).

Los defensores del concepto de economía campesina recurrieron nuevamente a la sociología para argumentar que la categoría permite analizar una forma de organización social que se articula y conecta con la capitalista en cuanto intercambian bienes y servicios. Con la articulación terminaron por enmendar la forma de agricultura caracterizada por el CIDA, "multifamiliar de gran tamaño", para bautizarla "agricultura empresarial" y atribuirle una racionalidad diferente de la campesina, la de tipo capitalista.

Quienes sostienen la economía campesina citan a Chayanov, Shanin y Tepicht. Sin embargo, no retoman la idea de Tepicht relativa a la participación de la economía campesina en el ámbito nacional. Al retomar a Carlos Marx, Tepicht (1973) considera que la economía campesina no es sui generis, dotada de una propia racionalidad, sino que está inmersa al interior del capitalismo y de su mercado. Allí es donde crece y se desarrolla con sus propios principios organizativos. Esta posición es sostenida por Alain de Janvry para la realidad latinoamericana, pues argumenta que en el sector 
campesino tanto los semiproletarios como los agricultores familiares se encuentran profundamente integrados en la economía capitalista mediante salarios y venta de productos (De Janvry 1981:239-242).

Sin necesidad de referirse a la articulación entre lógicas de producción, persiste la idea acerca de la existencia de formas diferentes de racionalidad entre la agricultura familiar y la empresarial. Se sostiene que el agro se caracteriza por una "estructura bimodal", es decir, se verifica la "coexistencia de una agricultura empresarial y una campesina", considerada esta última como sinónimo de economía familiar. Quienes hablan de estructura bimodal en el agro pretenden diferenciar las estrategias de la agricultura familiar de la empresarial con el fin de "ejecutar políticas o programas diferenciales según el tipo de productor" (Schejtman, 1998).

El examen de los cambios que acontecen en la tipología de los productores rurales me permite llegar a la conclusión de que la aproximación conceptual de la tipología es inadecuada porque desdibuja la agricultura familiar rindiéndola ambigua. Tal ambigüedad impide toda elaboración teórica sustentada en la información empírica existente y distorsiona aún más su empleo—si no es que vuelve inviables las políticas públicas que se diseñan con base en esa tipología.

La ambigüedad del concepto de agricultura familiar se ve favorecida porque se considera a este tipo de agricultura como una novedad, sin pensar que puede tener una historia más que secular. En efecto, la agricultura familiar nace y se consolida con los grandes cambios que ocurren en el subcontinente (América Latina) entre 1850 y 1970. Las revoluciones liberales y el orden liberal de los siglos XIX y XX, primero, y los gobiernos nacional-populistas del segundo tercio del siglo XX, subsecuentes, desarticulan la propiedad agraria de la Iglesia, legalizan la apropiación de tierras públicas o baldíos por agricultores sin tierra, favorecen los procesos de colonización agrícola en regiones fronterizas, y finalmente las reformas agrarias desarticulan la unidad productiva al fragmentar la gran propiedad (Carmagnani, 2004; Llambi, 1989).

Uno de los primeros en poner en evidencia el factor dinámico que representa la agricultura familiar es el autor del estudio del CIDA sobre Brasil. Ernest Feder argumenta que los niveles de pobreza rural en el subcontinente afectan a $65 \%$ de las familias rurales (4.3 millones en 1960) y pueden combatirse con el reforzamiento de la agricultura familiar. La viabilidad de esta forma de agricultura la ilustra a partir de los Censos Agropecuarios de 1950 y 1960, según los cuales la agricultura familiar no obstante que representa apenas $5.2 \%$ de la superficie agropecuaria y $2.6 \%$ de la tierra cultivada, genera $31.7 \%$ de producción agropecuaria total del subcontinente (Feder, 1972:261-266). 
Entre la década de los setenta y los primeros años del nuevo siglo se difunde la idea de que la agricultura familiar es el segmento más dinámico. Las nuevas estrategias y derechos del presente siglo favorecen el desarrollo territorial descentralizado, el derecho a la alimentación y la seguridad alimentaria, y ubican como el principal actor social al agricultor familiar (Gordillo, 2003:34-70 y Gordillo, 2004:76-78).

La crítica a la tipología sociológica aquí descrita me lleva por tanto a proponer un nuevo acercamiento a la definición de agricultura familiar. Mi punto de partida es que la agricultura familiar es difícil de reconocerse no tanto porque - como sostuvo Chayanov- incluya una serie "de complicaciones que derivan de la naturaleza de la actividad agrícola y, en especial, de la estructura de la producción agrícola y ganadera". Sin embargo, Chayanov indicó que cualquier unidad productiva independientemente de su forma "combina cuantitativa y cualitativamente tierra, trabajo y capital" (Chayanov [1921] 1966:90-92). Esta construcción mental — combinar cantidad y calidad de tierra, trabajo y capital— reduce la complejidad empírica del mundo rural y permite hacer inteligible el fenómeno agricultura familiar sin separarla de la racionalidad agraria y económica.

La pertenencia a una única racionalidad se puede observar al examinar a los actores presentes en cualesquiera de las formas agrícolas y rurales. Todos ellos poseen una pluralidad de activos de naturaleza económica (productivos y de mercado), social, política y cultural que utilizan para elaborar estrategias que favorecen su progreso individual y familiar que se traducirá en la modernización de la agricultura. Entonces debemos preguntarnos cuáles son los mecanismos necesarios para hacer converger las diversas estrategias individuales con las estrategias sociales; es decir, cómo inciden las preferencias individuales en las decisiones familiares, in primis, y cómo las preferencias y decisiones individuales y familiares repercuten en las decisiones en favor de la comunidad, o sea, de la localidad, la región y el país.

Al tomar decisiones todos los actores rurales buscan combinar sus activos productivos con los derivados de su participación en el mercado y en los servicios públicos y privados. Ello significa que no hay hostilidad predeterminada de los actores rurales hacia el mundo no rural y hacia el mercado. En efecto, con el proceso continuo de toma de decisiones cualquier actor rural puede obtener beneficios de su relación con el mercado gracias a su libertad de planear y replantear sus propias estrategias individuales, y a la vez oponerse a ciertas normas del mercado; sin que ello signifique declararse contrario o enemigo del mercado o de la estructura de poder existente en el mismo. La acción de los actores rurales tiende a concentrarse, sobre todo, en la trasformación de la estructura de poder del mercado con el fin de ampliar las oportu- 
nidades de acceso existentes. Cuando reaccionan, aparentemente en contra del "mercado-amenaza", se debe a que es producto de la estructura de poder presente en los mercados imperfectos. En cambio, el actor rural actúa positivamente cuando se logra potenciar el "mercado-amigo", aquél en el cual los actores sociales pueden utilizar al máximo sus propios mecanismos de decisión y, en consecuencia, ejercer su propia libertad de acción (Carmagnani y Gordillo de Anda 2000:9-15).

El punto de partida de mi análisis coincide con el de Chayanov, quien sostiene que "en la organización de un predio familiar uno de sus elementos es fijo, en cuanto depende del tamaño de la familia, lo cual obliga a colocar los otros factores - tierra y capital — en la mejor relación posible con el elemento fijo, es decir, la cantidad de trabajo de que dispone un predio familiar". Agrega que el tamaño de la familia no determina el tamaño del predio y la composición de todos sus elementos familiares porque un incremento productivo que obliga a una mayor intensidad del trabajo es inaceptable para la familia por el simple hecho de que afecta todos los activos materiales e inmateriales y compromete, en última instancia, su libertad de decisión (Chayanov [1921] 1966:92).

Si se difunde la idea de centralidad de la familia en la toma de decisiones, se logra establecer una conexión entre producción y mercado, lo que viene a ser considerado como un activo más a disposición de los individuos y de la familia. A lo anterior debe sumarse la trascendencia de los ingresos de origen no agrícola para la agricultura familiar que, sin duda, es — como se observará en las páginas subsecuentes— de las más relevantes aportaciones de los estudios de la década pasada.

Los ingresos rurales de origen no agrícola son importantes en el ámbito cuantitativo: la Organización de las Naciones Unidas para la Agricultura y la Alimentación (FAO, por sus siglas en inglés) estima que a mediados de los años noventa esta forma de ingreso representa $40 \%$ del total familiar y es generado con un empleo no agrícola que empeña $25 \%$ de la población rural (FAO, 1998, III, 6). Este ingreso tiene también una importancia cualitativa, pues genera vínculos con el sector no agrícola, empujándolo a incrementar su disposición a participar de la oferta de bienes y servicios a los predios familiares (upstream linkage) y a elevar su capacidad de ofrecer servicios de comercialización para los productos con un alto contenido de producción agrícola (downstream linkage).

Sí se toman en cuenta estos activos se puede arrojar luz no sólo en torno a las estrategias productivas sino también acerca de las de empleo, educación, políticas y de mercado de las unidades productivas. Por lo mismo, se pueden comprender mejor las distancias que existen al interior de la agricultura familiar y entre los dife- 
rentes predios. Estas distancias atañen tanto a la productividad como a los costos de transacción. En el ámbito de la productividad la distancia deriva de la incidencia de las variaciones de intensidad en el uso del trabajo familiar y de los factores técnicos productivos (maquinaria, instalaciones, etcétera) en los precios de los factores de producción debido a las imperfecciones del mercado (Ellis, 1988:201-209). En cambio, los costos de transacción inciden en la distancia física entre las unidades productivas de una misma localidad y en la distancia geográfica entre las unidades productivas y el resto del mundo (Primi, 2002).

Productividad y costos de transacción son susceptibles de ser visualizados en los costos constantes de las unidades productivas (insumos y costo del trabajo contratado), en los costos decrecientes (amortización de la tierra, maquinaria y edificios) y en los costos crecientes derivados de la distancia geográfica (transporte) y del acceso a los servicios públicos. Dicho de manera directa, por distancia debe entenderse que dos predios con la misma calidad y cantidad de tierra, trabajo y capital colocados en el mismo territorio o en territorios diferentes pueden tener costos diferentes y, por tanto, ingresos diferenciados.

En síntesis, el análisis que realizo de los censos agropecuarios toma en consideración los estudios existentes de siete países latinoamericanos, y tiene como objetivo reconocer, caracterizar y especificar la categoría de agricultura familiar con base en tres tesis que procedo a fundamentar. La primera mostrará cómo los actores rurales elaboran estrategias capaces de combinar la pluralidad de los activos disponibles. La segunda tesis sostiene que las estrategias no son uniformes, sino diferenciadas pero todas conducen o pueden ser encauzadas a una racionalidad común. La tercera, que la distancia existente entre las unidades productivas permite establecer el nivel de ingreso y egreso de la agricultura familiar e identificar el modo de integrar las unidades productivas excluidas de esta forma de agricultura, considerada como un instrumento para superar la pobreza del agro.

\section{Las informaciones nacionales}

\section{Brasil}

El Censo Agropecuario 1996 (CA 1996) constituye la mejor fuente para comprender la relevancia de la agricultura familiar en Brasil así como las variables que la caracterizan. En efecto, el CA 1996 establece la distinción por superficie de unidad productiva, por trabajo familiar y por trabajo no familiar incorporado, la inversión en tierra, instalaciones, cultivos, mecanización y, lo que no es frecuente en otros censos 
agropecuarios, incorpora el gasto e ingreso por unidad productiva (Censo Agropecuario de 1995-1996, www.ibge.gov.br).

Cuadro 1

Tierra, trabajo, capital e ingresos

\begin{tabular}{|c|c|c|c|c|c|c|c|c|c|c|c|}
\hline \multicolumn{2}{|c|}{ Tierra } & \multicolumn{3}{|c|}{ Trabajo } & \multirow[b]{2}{*}{ 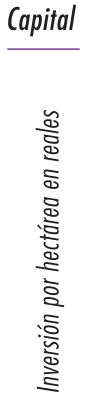 } & \multicolumn{6}{|c|}{ Ingreso } \\
\hline 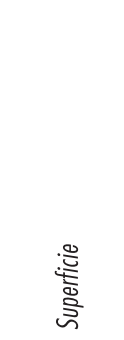 & 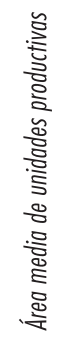 & 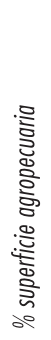 & 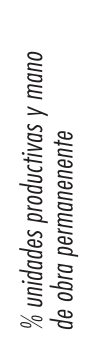 & 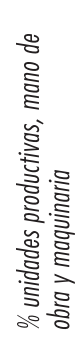 & & 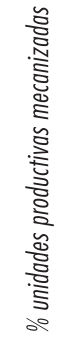 & 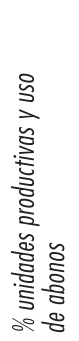 & 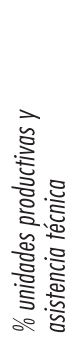 & 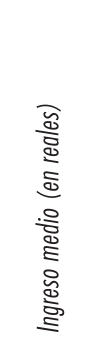 & 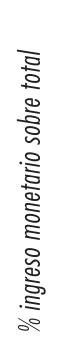 & 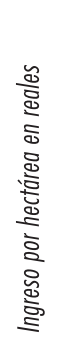 \\
\hline-5 ha & 1.9 & 6.8 & 9.7 & 4.8 & 18.5 & 22.0 & 24.4 & 8.6 & 104 & 6.1 & 6 \\
\hline 5-20 ha & 10.7 & 9.6 & 20.5 & 4.6 & 11.5 & 22.2 & 32.7 & 11.9 & 714 & 53.6 & 60 \\
\hline 20-50 ha & 31.0 & 5.2 & 15.5 & 7.2 & 18.1 & 32.4 & 50.6 & 25.1 & 2,172 & 62.2 & 103 \\
\hline $50-100$ ha & 67.8 & 8.9 & 31.1 & 10.2 & 46.7 & 52.1 & 69.2 & 44.0 & 11,898 & 74.4 & 269 \\
\hline
\end{tabular}

Fuente: Censo Agropecuario 1996.

A partir de la desagregación de activos y de ingresos de predios inferiores a 50 hectáreas (ha) que considera el censo y del análisis del área de agricultura familiar se desprende que la agricultura patronal se identifica con las unidades productivas de un área superior a las 50 ha pero que de hecho prevalece la unidad superior a las 100.

El primer problema es determinar si las unidades productivas caracterizadas como "periféricas" —es decir, las que tienen una superficie media de 1.9 ha como aparece en el cuadro 1- también forman parte de la agricultura familiar. A la variable de superficie es importante valorar otros numerosos aspectos: un bajo porcentaje de mano de obra y de mecanización, el escaso uso de fertilizante, la carencia de asistencia técnica. Por lo cual además tienen un ingreso medio seis veces inferior al percibido en los predios con una superficie media de 10 ha, un ingreso por hectárea que es apenas $10 \%$ de las unidades productivas del estrato siguiente de productores y, finalmente, este tipo de unidad familiar tiene una escasa vinculación con el mercado, pues sólo $6.1 \%$ de sus ingresos es monetario, 
El hecho de que se hubiera dejado de considerar como agricultura familiar a casi dos millones de unidades productivas (1.9 millones) con una superficie media de 1.9 ha deriva de dos consideraciones. La primera, que mientras el valor bruto de la producción — de este estrato— es de una media de 101.40 reales ( $\mathrm{R} \$$ ), al año su ingreso medio anual —obtenido en las actividades agrícolas y no agrícolas — fluctúa entre $\mathrm{R}$ \$701-780 según la región. Además, de acuerdo con cálculos muy precisos, el autoconsumo representa $24 \%$ del valor total de la producción agrícola en este tipo de unidades (Leite, 2004:128-129).

Si se parte de la premisa de que este sector de productores de subsistencia ocupa $6.8 \%$ del área total agropecuaria que produce sólo $4.1 \%$ de la producción agropecuaria total, se llega a la conclusión de que sobrevive gracias al salario o actividades externas a la agricultura; ingresos por cuenta propia (pequeño comercio y artesanías) obtenidos en áreas rurales o ciudades. Se ha señalado, en efecto, que el contrapunteo entre agricultura de subsistencia y sistemas productivos altamente especializados favorece una actividad de autoconsumo; e incluye los bienes que son al mismo tiempo objeto de trueque entre vecinos o de ventas en ferias locales. Estas actividades son las que generan el ingreso extraagrícola extrapredial que permite la sobrevivencia de estos productores marginales (Wilkinson, 2004:102-103).

El cuadro 1 muestra que la agricultura familiar se manifiesta con relativa claridad en las unidades productivas con tierras de entre 10.7 y $67.8 \mathrm{ha}$. Dicho cuadro destaca la viabilidad de la agricultura familiar en una unidad productiva cuya superficie es entre 10.7 y 67.8 ha. Son unidades productivas con grado de combinar la mano de obra familiar con la temporal y la permanente; cuentan con un alto nivel de mecanización (tractores y vehículos de transporte), fertilizan los campos, tienen un adecuado nivel de inversión por hectárea en la producción. En particular, las unidades productivas con más de 67.8 ha son las que tienen más posibilidad de acceso a la asistencia técnica y finalmente son las más integradas al mercado porque más de la mitad de sus ingresos totales es monetaria.

Un interés particular presenta la franja de agricultura con tierras entre 5 y 20 ha. Ciertos indicadores dejan ver algunos rasgos de las unidades productivas comprendidas entre los 31 y 67.8 ha que, como se ha dicho, son las que mejor reflejan los rasgos óptimos de la agricultura familiar.

En efecto, la distancia entre el ingreso total promedio del estrato de tierras comprendidas entre 5 y 20 ha $(\mathrm{R} \$ 714)$ del ingreso promedio del estrato siguiente — de 20 a 50 ha (R\$2,172) — es elevada. Sin embargo, el hecho más significativo es que la franja que se encuentra entre 5 y 20 ha obtiene más de la mitad de sus ingresos 
(53.6\%) de la actividad predial. Estas unidades integran la mano de obra familiar con mano de obra externa y una parte significativa de sus producciones las transforman en bienes destinados al mercado.

El hecho de que los productores con tierras entre 5 y 20 ha no se consideren —de modo pleno- en el rango de la agricultura familiar se debe a la escasa inversión por hectárea, la reducida capacidad para tener acceso a la asistencia técnica y, como se observa en el cuadro 2, a la escasa capacidad de organizarse en asociaciones o de articularse con otras formas asociativas.

La hipótesis que se puede formular es que las unidades productivas del estrato comprendido entre 5 y 20 ha encuentran una serie de obstáculos para su plena participación en la agricultura familiar. A saber, producto de su baja integración en los programas de desarrollo rural por la ausencia de canales apropiados para obtener crédito para participar en el mercado, ya sea para tener acceso a formas de arrendamiento de maquinaria agrícola o créditos e insumos mediante su asociación con otras organizaciones rurales.

Cuadro 2

Trabajo, ingresos y participación social de los agricultores familiares

\begin{tabular}{|c|c|c|c|c|c|c|c|c|}
\hline \multirow[t]{2}{*}{ Superficie } & \multirow{2}{*}{$\begin{array}{l}\text { Trabajo } \\
\\
\begin{array}{l}\text { Trabajo } \\
\text { temporal }\end{array}\end{array}$} & \multirow{2}{*}{$\begin{array}{c}\text { (trabajadores } \\
\text { por unidades } \\
\text { productivas) }\end{array}$} & \multicolumn{2}{|c|}{ Ingreso total $x$} & \multicolumn{2}{|c|}{$\mathrm{Ha}$ (reales) } & \multicolumn{2}{|c|}{ Asociacionismo } \\
\hline & & & $\begin{array}{c}\text { Muy } \\
\text { especializado }\end{array}$ & Especializado & Diversificado & $\begin{array}{c}\text { Muy } \\
\text { diversificado }\end{array}$ & $\begin{array}{c}\text { Muy } \\
\text { diversificado }\end{array}$ & $\begin{array}{l}\text { (\% unidades } \\
\text { productivas) }\end{array}$ \\
\hline-5 & 0.15 & 0.07 & 4 & 3 & 15 & 25 & 25 & 5.7 \\
\hline $5-20$ & 0.45 & 0.12 & 75 & 61 & 58 & 62 & 62 & 9.4 \\
\hline $20-50$ & 0.20 & 0.04 & 135 & 109 & 94 & 105 & 105 & 19.9 \\
\hline $50-100$ & 3.40 & 0.29 & 446 & 322 & 201 & 205 & 205 & 34.2 \\
\hline
\end{tabular}

El cuadro 2 indica que la agricultura familiar no puede crecer sin el aporte del trabajo no familiar y que su tendencia es utilizar trabajo temporal para siembra y cosecha, mientras las unidades productivas que superan las 30 ha comienzan a necesitar mano de obra permanente.

Si examinamos - siempre en el cuadro 2 - las fuentes del ingreso total, observamos que - con excepción de las unidades menores de 5 ha- las producciones muy especializadas proporcionan un mayor ingreso, mientras las ganacias derivadas de 
las producciones muy diversificadas ocupan el segundo lugar. Se podría pensar que la agricultura familiar tiende a desarrollar una estrategia productiva que combina produccion altamente especializada con la muy diversificada. Probablemente esta estrategia es la respuesta a la incertidumbre del ingreso que proviene del spot market, al cual se orientan las producciones altamente diversificadas, y a la regularidad del ingreso que se obtiene en el contract market gracias a que las producciones más especializadas se suelen contratar a futuro.

El análisis del Censo Agrícola de Brasil 1995-1996 permite reelaborar los datos censales y exponer la siguiente hipótesis: de los 4.8 millones de productores considerados genéricamente por el censo como unidad familiar, sólo 1.7 millones de productores - de los que trabajan 54.4 millones de ha (16.3\% de la superficie agropecuaria) - tienen una lógica productiva y desarrollan las estrategias propias de una agricultura familiar viable. Existen otros 823 mil productores que trabajan 18 millones de ha que podrían — con el apoyo de políticas públicas adecuadas: de arriendo de tierras, organización en cooperativas y mayor acceso al crédito- integrarse a la agricultura familiar. Ésta genera una producción de $\mathrm{R} \$ 14.5$ mil millones, equivalente a 30.3\% de la producción agropecuaria total, y la integración de los productores marginales elevaría su participación en la producción total a 33.9\%.

De la información censal analizada están excluidos los integrantes de las familias de agricultores que laboran en actividades externas a esta rama y que complementan los ingresos de la agricultura familiar (Graziano da Silva, 2001). A diferencia de miembros de la familia de unidades productivas marginales o de subsistencia, los sujetos externos a la agricultura familiar tienen la capacidad de reforzarla, con lo que alientan el desarrollo rural. En efecto, esta actividad generó entre 1981 y 1997 una expansión de la fuerza laboral residente en las áreas rurales de $2.5 \%$ anual y estableció una continuidad entre residencia urbana y actividad rural (Del Grosso y Graziano da Silva, 1998). La agricultura familiar favoreció también la diferenciación entre los actores rurales y potenció las dinámicas subyacentes a la oferta y demanda en los mercados no agrícolas, así como los eslabonamientos entre el sector agrícola y no agrícola (Graziano da Silva y Del Grosso, 2004:78-82) Igualmente este tipo de agricultura favoreció las actividades derivadas de la producción de bienes y servicios agrícolas e indirectamente su comercialización (Graziano da Silva, Del Grosso y Laurenti, 1999).

\section{Uruguay}

El Censo General Agropecuario 2000 (CGA 2000) se elaboró a partir de la información proporcionada por las unidades productivas de gerencia única. La definición de 
éstas considera la tierra dedicada parcial o totalmente a fines agrícolas, pecuarios y forestales de una hectárea o más de superficie. Además deben haberse desarrollado actividades agropecuarias por lo menos durante una parte del año censal. En este caso se refieren los datos al periodo del 1 de julio de 1999 al 30 de julio de 2000 (CGA, Recuentos preliminares, www.mgap.gub.uy).

\section{Cuadro 3}

Unidades productivas, superficie media e índice de explotación

\begin{tabular}{rcccc}
\hline Superficie & \% unidades productivas & \% superficie nacional & $\begin{array}{c}\text { Índice de explotación } \\
1990=100\end{array}$ & \begin{tabular}{c} 
Superficie media (ha) \\
\hline $1-4$
\end{tabular} \\
\hline 11.1 & 0.1 & 143.4 & 2.6 \\
$10-9$ & 12.4 & 0.3 & 107.1 & 6.7 \\
$20-49$ & 12.5 & 0.1 & 98.8 & 13.7 \\
$50-99$ & 15.6 & 1.7 & 98.4 & 31.9 \\
$100-199$ & 11.7 & 2.9 & 102.4 & 71.1 \\
$200-499$ & 11.2 & 5.5 & 101.0 & 142.5 \\
$500-999$ & 11.8 & 13.2 & 99.6 & 318.5 \\
$+1,000$ & 6.7 & 16.6 & 99.2 & 700.9 \\
\hline
\end{tabular}

Fuente: Censo General Agropecuario 2000.

La información — publicada — registra la explotación por tamaño, el índice de la explotación (con base 1990=100), la superficie en cultivo por tamaño de la unidad y el índice de la explotación o unidad productiva por fuente de ingreso principal. Por desgracia este último dato no está desagregado según el tamaño de la explotación.

La información publicada indica que las unidades productivas inferiores a las 20 ha ocupan apenas $0.5 \%$ de la superficie agropecuaria total (161,900 ha), además de haberse reducido entre 1980 y 2000 . Es probable que el segmento de predios menores a 5 ha sea de horticultura o de tipo turístico, vacacional o de segunda residencia. Estas unidades, que suman 39\% de todas las censadas, se encuentran en manos de propietarios que desarrollan su actividad en la ciudad y, en especial, en Montevideo.

A pesar de su reducida participación en la superficie total agropecuaria, las 20,561 unidades de superficie media entre 2.6 y 13.7 ha se caracterizan por una alta productividad. Este segmento agrícola, en especial el de una superficie media entre 2.6 y 6.7 
ha, es el único que ha visto crecer su índice de producción en el periodo 1991-2000. La unidad productiva cuya extensión media es de 2.6 ha aumentó su índice de explotación de $43.4 \%$, mientras que las de extensión media de 6.7 ha apenas crecieron de $7.1 \%$.

Un estudio reciente que utiliza como fuente el CGA 2000 permite integrar la información aquí expuesta. El trabajo recoge los datos relativos al uso de la tierra por estrato conforme al tamaño del predio y proporciona información adicional desagregando las hectáreas que en cada estrato han sido mejoradas y fertilizadas.

Cuadro 4

Uso de la tierra

\begin{tabular}{lcccc}
\hline \multicolumn{1}{c}{ Uso tierra } & \% Superficie total & \multicolumn{3}{c}{ Participación en la superficie total } \\
\cline { 3 - 5 } & & $0-49$ ha & $50-99$ ha & 100-199 ha \\
\hline Pradera artifificial & 8.1 & 3.2 & 5.6 & 9.2 \\
Campo mejorado & 4.9 & 1,4 & 2.5 & 5.0 \\
Campo fertilizado & 0.7 & 1.3 & 2.7 & 5.7 \\
Cultivo forraje anual & 1.9 & 3.2 & 5.8 & 9.4 \\
Huertas, frutal, viñedos & 0.1 & 1.9 & 11.8 & 11.8 \\
Tierras de labranza & 3.1 & 4.6 & 5.1 & 8.0 \\
Montes artificiales & 3.9 & 0.5 & 0.9 & 2.4 \\
Campo natural & 77.3 & 2.2 & 3.1 & 6.6 \\
\hline
\end{tabular}

Fuente: Uruguay Agroalimentario 2002-2004.

Los datos censales directos e indirectos permiten definir el sector agricultura familiar a partir del diferencial entre los distintos estratos según la extensión de la unidad productiva. La hipótesis es que la unidad con una superficie que fluctúa entre 6.7 y 13.7 ha constituye el límite inferior viable de la agricultura familiar uruguaya.

Con el fin de establecer el límite superior de la agricultura familiar conviene examinar las diferencias y los puntos de contacto que se dan en el uso del suelo y en mejoras o adelantos por unidad (cuadro 5). Por ello se desglosa la unidad productiva del estrato: de 0 a 49 ha y los dos estratos siguientes, 50-99 y 100-199 ha.

Llama la atención que $77.3 \%$ - es decir, dos tercios de la superficie agropecuaria uruguaya- refleje un bajo uso del suelo; ello es porque se deja el campo al natural, sin explotar, lo cual habla del predominio de la actividad ganadera visible en unidades de más de 200 hectáreas. 
Con base en un breve comentario del resultado preliminar del CGA 2000, leemos que las grandes explotaciones $(31,849)$ representan $55.7 \%$ de las unidades productivas $(57,115)$, lo cual significa que toda propiedad de más de 100 ha es considerada una gran explotación. La extensión de gran explotación es de 13.4 millones de ha, y de esta superficie $82 \%$ se destina a la ganadería, en especial al ganado vacuno que se duplicó entre 1990 y 2000.

Si se descuenta la superficie ganadera, comprendido el campo natural y las praderas artificiales, la restante representa apenas $10.8 \%$ de la superficie agropecuaria, equivalente a 1.73 millones de ha. Los 1.7 millones de ha restantes se dividen entre unidades productivas con una superficie media que fluctúa entre 2.6 y 71.1 ha.

Cuadro 5 Nuevos mejoramientos por estrato de tamaño

\begin{tabular}{lcccccc}
\hline & \multicolumn{5}{c}{ Porcentaje de los mejoramientos nacionales } \\
\cline { 2 - 7 } & $0-49$ & $50-99$ & $100-199$ & $200-499$ & $500-999$ & +1000 \\
\hline Praderas artificiales & 2.4 & 5.2 & 9.3 & 17.6 & 17.5 & 47.8 \\
Siembras en cobertura & 0.7 & 1.9 & 3.7 & 12.5 & 19.2 & 61.9 \\
Siembras a zapata & 0.9 & 2.7 & 6.3 & 17.3 & 15.3 & 57.5 \\
Campo natural fertilizado & 1.1 & 2.8 & 5.2 & 12.2 & 18.7 & 60.0 \\
\hline
\end{tabular}

Fuente: Uruguay Agroalimentario 2002-2004.

Las mejoras o innovaciones en el uso del suelo se concentran en la propiedad que superan las 200 ha. Es probable que se trate de propiedades con tierras subutilizadas y que se benefician con inversión nueva. En cambio, en la unidad productiva menor a 200 ha es baja la propensión a beneficiar la tierra y modificar el uso del suelo. La débil propensión a la innovación es aún más notoria en la propiedad inferior, es decir, a la que fluctúa entre 0 y 49 ha.

El incremento espectacular de la ganadería vacuna y la reducción del ganado ovino en relación con el escaso adelanto o mejora en la agricultura familiar indica que, en el caso de Uruguay, la agricultura empresarial se ha convertido en la más dinámica.

En consecuencia, la distribución del ingreso rural muestra que casi la mitad del ingreso percibido por los hogares de productores agrícolas proviene de una actividad externa que aumenta cuando el ingreso es más alto. A su vez —en el caso de ciudades 
Gráfica 1

Participación del ingreso agropecuario en el ingreso rural según nivel de ingreso, 2000

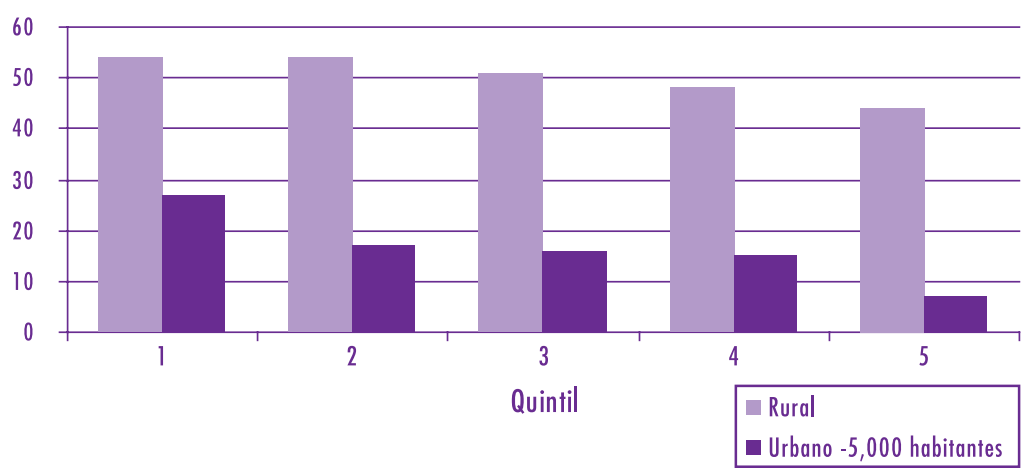

Fuente: OPYPA-MGAP, Empleo, ingreso y condiciones de vida en los hogares rurales, 2004.

menores a 5,000 habitantes - los ingresos que llegan de la actividad agropecuaria muestran el eslabonamiento entre agricultura familiar y actividad rural no agrícola.

En Uruguay destaca también la agricultura familiar dedicada a la fruticultura, viticultura, horticultura, cereales y lechería. La superficie de tierra de que disponen estas unidades productivas fluctúa entre 6.7 y 71.1 ha y que comprende $10.6 \%$ de la superficie total agropecuaria.

\section{Argentina}

El Censo Nacional Agropecuario 2002 (CNA 2002) utiliza los siguientes criterios: 1) la unidad estadística es la explotación agropecuaria (EAP), el productor agrario es la persona física o jurídica quien en calidad de propietario, arrendatario, aparcero, contratista accidental u ocupante, ejerce el control técnico y económico de la EAP (CAN 2002, www.indec.gov.ar).

A pesar de la excelente calidad del censo, sólo unos cuadros ofrecen la información necesaria para poder definir la parte de las EAP pertenecientes a la agricultura familiar. De los 30 cuadros del CAN 2002 sólo uno permite ver la extensión de las EAP, y dos de éstos contienen información relativa a las personas residentes como la ocupación que ejercen en la EAP. El censo nada dice de la inversión, el ingreso y la integración al mercado por estratos de superficie. 
Cuadro 6

Distribución de las explotaciones agropecuarias (EAP)

\begin{tabular}{rrrccc}
\hline & Núm. EAP & Extensión(ha) & Extensión1/2 EAP (ha) & \% EAP & \% sobreextensión total \\
\hline-5 & 40,957 & 105,895 & 2.6 & 13.7 & 0.60 \\
$5-10$ & 22,664 & 177,973 & 7.8 & 7.6 & 0.10 \\
$10-25$ & 39,833 & 714,584 & 17.9 & 13.3 & 0.40 \\
$25-50$ & 33,787 & $1,290,129$ & 38.2 & 11.3 & 0.73 \\
$50-100$ & 34,881 & $2,660,005$ & 76.3 & 11.7 & 1.52 \\
$100-200$ & 34,614 & $5,150,390$ & 148.8 & 11.6 & 2.94 \\
$200-500$ & 40,211 & $13,113,229$ & 326.1 & 13.5 & 7.50 \\
\hline
\end{tabular}

Fuente: Censo Nacional Agropecuario 2002.

Se optó por seleccionar como unidad productiva la de superficie inferior a 500 hectáreas porque representa $82.7 \%$ del total de los productores, no obstante que ocupa sólo $13.8 \%$ de la superficie agropecuaria total. Además se tomó en cuenta lo establecido en el informe de la Secretaría de Agricultura, que sostiene que entre el CNA 1988 y el CNA 2002, para la zona del núcleo agrícola de las provincias de Buenos Aires, Córdoba y Santa Fe, hubo "una gran caída en el estrato de hasta 500 ha (-34\% en cantidad de EAP y -26\% en superficie ocupada por este estrato). En cambio, el mayor aumento se registra en los estratos de 2,500 a 10,000 ha; $+6 \%$ en cantidad de EAP y $+5 \%$ en superficie" (Secretaría de Agricultura, Ganadería Pesca y Alimentos, 2004). Esta baja en la superficie que ocupan las EAP, que podrían ser consideradas como unidades familiares, se explica sobre todo por la disminución de EAP de hasta 50 ha (Carballido, 1004:7-8).

Se puede formular la siguiente hipótesis: las EAP de menos de 50 ha, cuya extensión media es de 38.2, constituyen unidades subfamiliares. Son tendencialmente de agricultura de subsistencia, destinadas a ser incorporadas en predios mayores o transformadas en segundas residencias, lugares de turismo o zonas suburbanas.

Las unidades productivas con una extensión media de 38.2 ha son aquellas que "no proveen de empleo remunerativo de la familia usando los recursos técnicos prevalecientes en la región de acuerdo con los valores locales" (Tort, Bearzotti, Neiman 1991:567-569). En efecto, según las encuestas agrarias de fin de la década de los ochenta, la agricultura familiar en la provincia de Buenos Aires la constituyen las EAP con una extensión promedio de 149 ha, donde la actividad más importante es la agricultura. Las mismas encuestas muestran que en la provincia de Santa Fe la superficie 
media de las EAP familiares es de 134 ha y se caracterizan como "familiar combinada", porque complementa la actividad agrícola en el propio predio con la realizada en tierras tomadas en arriendo o mediería. La misma característica se encuentra en las provincias de Buenos Aires y Córdoba.

En Buenos Aires el trabajo que requiere la agricultura familiar lo proporcionan en $90 \%$ los miembros de la familia y el 10 restante el peón transitorio. En Córdoba, $44 \%$ de las unidades productivas familiares contrata mano de obra asalariada. (Sola, 1991:476-478). Se puede agregar que, tal como acontece en Uruguay, la agricultura familiar se dedica casi exclusivamente a la producción agrícola pero, a diferencia de la uruguaya, la argentina privilegia la innovación tecnológica que no requiere de fuerte inversión y que no necesita incorporar asalariados. De allí la importancia dada a los herbicidas, a las semillas mejoradas, a los implementos (Sola, 1991:478-479).

La información relativa a las personas que trabajan en las EAP nos permite diferenciar mejor la agricultura de subsistencia, marginal o mal definida subfamiliar de la propiamente familiar. Las EAP con una extensión de entre 38 y 148 ha son 103,382 y emplean a 182,986 miembros de familia, es decir, 1.8 unidades de trabajo por EAP.

Cuadro 7

Unidades productivas, superficie y mano de obra

\begin{tabular}{lrrrrcc}
\hline & Núm. EAP & Superficie & $\begin{array}{c}\text { Mano de obra } \\
\text { total }\end{array}$ & $\begin{array}{c}\text { Extensión } \\
\text { 1/2 EAP (ha) }\end{array}$ & $\begin{array}{c}\text { Trabajadores } x \text { EAP } \\
\text { (unidades) }\end{array}$ & $\begin{array}{c}\text { Trabajadores } x \text { EAP } \\
\text { (unidades) }\end{array}$ \\
\hline EAP subfamiliar & 103,454 & 998,452 & 183,113 & 9.6 & 1.8 & 5.4 \\
EAP familiar & 103,382 & $6,706,524$ & 182,986 & 64.9 & 1.8 & 36.6 \\
EAP empresarial & 90,589 & $167,104,000$ & 415,660 & $1,844.6$ & 4.5 & 40.2 \\
\hline
\end{tabular}

Fuente: Ministerio de Economía y Producción, Dirección de Desarrollo Rural con base en el CAN 2002.

El cuadro 7 permite observar que tanto la agricultura de subsistencia como la familiar encuentran su fuerza en la mano de obra de la familia. Sin embargo, esta última - 1.8 unidades - es capaz de poner en producción 5.4 ha en las EAP de subsistencia, mientras que en las EAP familiares la mano de obra familiar complementada con la contratada hace producir siete veces más, 37.8 ha. Si calculamos 
el esfuerzo productivo de 1.8 trabajadores en 30 horas a la semana, obtenemos 1,808 horas de trabajo anual para hacer productivas 5.8 ha de predios de subsistencia. Para hacer productivas las 36.6 ha de las EAP familiares se necesitarían 6.8 trabajadores, es decir, 10,608 horas de trabajo, de lo que resultaría un déficit de 8,800 horas.

Este cálculo nos permite argumentar —en ausencia de información acerca de inversión en instalaciones, tractores, sistema de regadío, refrigeración, etcéteraque la agricultura familiar argentina sustituye la fuerza de trabajo con un quantum significativo de inversión. De lo que resulta que la agricultura familiar presenta, sin lugar a dudas, un nivel de capitalización alto, más parecido a las EAP empresariales que a las de subsistencia. También se podría agregar que la distancia entre las EAP de subsistencia y las familiares es mucho más amplia del diferencial existente entre la actividad agrícola familiar y la actividad esencialmente pecuaria de la agricultura empresarial.

Vale la pena añadir que la extensión media de las EAP familiares no debe ser considerada un dato fijo e inmutable. En la región pampeana la dimensión media de las unidades varió de 121.3 a 358.8 ha, entre 1996 (año de precios internacionales excepcionales para una excelente producción de granos) y 1999 (año de fuerte depresión de precios internacionales de grano) (Lattuada, 2000). La agricultura familiar es muy sensible al incremento del precio de la tierra, porque muchas unidades requieren — como se ha dicho — ser complementadas por el arriendo que fluctúa según el precio de la tierra. La agricultura familiar es además sensible a las tasas de interés del crédito, cuyo incremento aumenta notablemente la tasa de morosidad de los productores familiares, como ocurrió entre 1989 y 1999. Sin embargo, el rasgo más significativo acerca del estancamiento de la agricultura familiar argentina en la última década del siglo pasado fue el registrado en las cooperativas agrícolas. Ello, no obstante el sostén ofrecido por el programa de cooperación entre las empresas agrícolas argentinas y europeas, mediante el programa Al-Invest de la Unión Europea (Lattuada, 2000).

Chile

La información que proporciona el Censo Agropecuario 1997 (CA 1997) es una de la más completas para América Latina, debido a que desagrega por estratos la tenencia, el personal y miembros del hogar que trabajan en la explotación, el uso del suelo, las producciones, la maquinaria y equipo agrícola y la infraestructura existentes en el mundo agropecuario (CA 1997, www.ine.cl). 
Cuadro 8

Tierra, trabajo y capital agropecuario

\begin{tabular}{|c|c|c|c|c|c|c|c|c|c|c|c|c|c|}
\hline \multirow[t]{2}{*}{ Superficie } & \multicolumn{2}{|c|}{ Unidades productivas } & \multicolumn{4}{|c|}{ Trabajo } & \multicolumn{7}{|c|}{ Capital } \\
\hline & 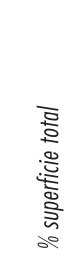 & 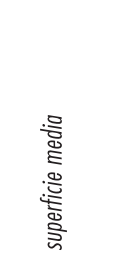 & 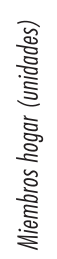 & 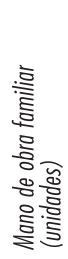 & 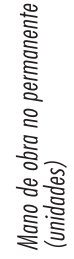 & 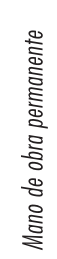 & 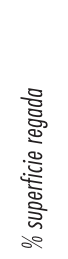 & $\begin{array}{l}\text { है } \\
\text { डे } \\
\text { छे } \\
\infty\end{array}$ & $\begin{array}{l}\text { है } \\
\text { 号 } \\
\frac{\bar{D}}{5}\end{array}$ & 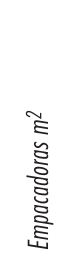 & 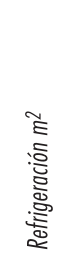 & 产 & 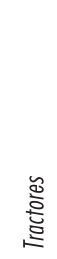 \\
\hline 1 & 14.9 & 0.5 & 4.4 & 1.4 & 3.4 & 2.0 & 64.4 & 11.3 & 0 & 0 & 0 & 0.0 & 0.0 \\
\hline $1-5$ & 29.6 & 2.4 & 4.2 & 1.6 & 4.1 & 2.5 & 39.4 & 42.9 & 24 & 587 & 13 & 1.08 & 0.53 \\
\hline $5-10$ & 15.9 & 7.1 & 4.3 & 1.8 & 4.6 & 2.8 & 34.7 & 539.0 & 103 & 504 & 3520 & 1.10 & 1.13 \\
\hline $10-20$ & 14.7 & 14.0 & 4.3 & 1.9 & 5.0 & 3.1 & 35.3 & 74.0 & 1377 & 578 & 1512 & 1.39 & 1.27 \\
\hline $20-50$ & 13.2 & 31.1 & 4.3 & 1.9 & 5.7 & 3.8 & 31.9 & 101.0 & 193 & 667 & 2802 & 1.17 & 1.49 \\
\hline $50-100$ & 5.5 & 68.5 & 4.3 & 1.9 & 7.3 & 5.4 & 30.1 & 186.0 & 225 & 768 & 2469 & 0.85 & 2.80 \\
\hline $100-200$ & 2.8 & 137.3 & 4.2 & 1.8 & 11.1 & 9.3 & 31.9 & & & & & & \\
\hline $200-500$ & 1.8 & 304.5 & 3.9 & 1.7 & 19.2 & 17.5 & 32.2 & 707.0 & 1178 & 1263 & 2335 & & \\
\hline+500 & 1.6 & 1993.1 & 3.9 & 1.6 & 55.0 & 53.4 & 32.3 & & & & & & \\
\hline
\end{tabular}

Fuente: Censo Agropecuario 1997.

En el universo agropecuario chileno la participación de las explotaciones inferiores a 50 ha representa $88.3 \%$ de las unidades productivas totales y cubre $9.2 \%$ de la superficie total agropecuaria (1.9 millones de ha). Ello significa que la distinción entre agricultura de subsistencia y agricultura familiar y/o empresarial se puede reconocer tanto en Chile como en Argentina.

La línea divisoria entre la agricultura familiar y la empresarial parece situarse en el estrato 50-100 ha y se percibe de la distancia que media entre las dos formas de actividad agropecuaria. Todas las unidades productivas de 0 a 50 ha utilizan la mano de obra familiar y se valen de cantidades similares de trabajo remunerado permanente y no permanente.

Vale la pena destacar que todos los predios inferiores a 50 ha necesitan contratar mano de obra. Precisamente porque incluso los predios inferiores de una hectárea contratan asalariados, a semejanza de Brasil y a diferencia de Argentina y Uruguay, en Chile existe una población rural que no tiene acceso a la tierra y al no disponer de otros activos se emplea de manera indiferente en la agricultura de subsistencia y en la familiar. La posibilidad de contratar mano de obra permite a los miembros de las familias agrícolas con tierras desplazarse hacia otras actividades donde generan un 
ingreso mayor que les permite pagar y permanecer con un excedente que destinan a la adquisición de bienes para la actividad productiva.

Diferenciar la agricultura de subsistencia de la familiar, como he venido haciendo, es una tarea más difícil en el caso de Chile, en relación con los otros dos países del Cono Sur. Complejo porque en las 41,441 unidades menores a una hectárea el censo incluye, a la vez, segundas casas que si bien pueden tener jardín y huerta — que por lo general cuida un asalariado — sirven fundamentalmente para el esparcimiento del propietario. Sólo así se explica que —-según el CA 1997-10.7\% de predios inferiores a una hectárea no tenga actividad productiva y sólo proporcione ocupación a $8.5 \%$ de la mano de obra total.

Por tanto, se logra avanzar en la distinción entre agricultura de subsistencia y agricultura familiar mediante la observación de los indicadores relativos al capital invertido en los predios. Mientras los predios de menos de una hectárea tienen un alto porcentaje de tierra regada (64.4\%), debido a que jardines y huertas requieren de irrigación, la constante en los predios de los estratos siguientes es irrigar casi un tercio de la superficie total. Al mismo tiempo, y a diferencia de los predios de menos de una hectárea y subsecuentes, no tienen instalaciones, camiones o tractores; lo que nos lleva a pensar que en este primer estrato la producción es de autoconsumo y la unidad agrícola sirve de sustento para que algunos integrantes de la familia se ocupen tiempo pleno o parcial en otras actividades rurales.

El CA 1997 destaca que el número de hogares con miembros trabajando en la agricultura y en actividades no agrícolas es el siguiente: a) 5\% de los hogares tienen familiares trabajando en la agricultura, b) $9 \%$ de los hogares tienen a parientes en empleos no agrícolas, y c) $6 \%$ de los hogares tienen uno o más miembros trabajando en el sector urbano. De allí que se pueda afirmar que $20 \%$ de los hogares agrícolas es pluriactivo, es decir, da vida a un mix de ingreso rural y urbano que explica la sobrevivencia de ese ámbito específico de agricultores (Berdegué et al., 2004:38-40).

Mayor homogeneidad presentan las unidades productivas cuya extensión de tierras fluctúa entre 2.4 y 31.1 hectáreas, porque combinan unidad de trabajo familiar con trabajo contratado relativamente similar, cuyo resultado indica que la mano de obra familiar contribuye con un tercio del trabajo total. La misma homogeneidad se encuentra en la mecanización y en las instalaciones: todas las unidades de ese rango tienen un coeficiente muy similar de inversión en camiones, camionetas y tractores, así como inversión fija en bodegas, establos, empaque y refrigeración. En efecto, los estratos comprendidos entre 5-10 y 20-50 ha poseen, cada una, un promedio de $75.9 \mathrm{~m}^{2}$ de bodegas, $14.2 \mathrm{~m}^{2}$ de establos, $70.9 \mathrm{~m}^{2}$ de empacadoras y $495 \mathrm{~m}^{3}$ de refrigeración. 
Los indicadores tierra, trabajo y capital nos hablan de que los establecimientos de una superficie de 5-10 ha y superior son viables económicamente, lo que se reconoce en la lógica de la agricultura familiar: $39.1 \%$ de mano de obra es familiar y su ingreso les permite invertir en sus predios.

El interés de los agricultores familiares en realizar inversión productiva se ha relacionado con el notable aumento de los precios de la tierra a partir de 1980. Entre 1980 y 1993 en el Valle Central —el área más rica de la agricultura chilena- el precio de la tierra de riego con plantación —en dólares de 1993 — aumentó 11.2\%; la de riego sin plantación $19.6 \%$ y la de secano $2.8 \%$. Incrementos similares tuvo el precio de la tierra en las regiones del centro-sur del país (Echenique, 1996:94-96).

Con base en lo anterior, se puede pensar que la agricultura familiar chilena comprende las explotaciones con una superficie que fluctúa entre 10 y 50 ha, segmento productivo que representa $43.3 \%$ de los productores, quienes poseen 1.8 millones de ha, de las cuales $33.9 \%$ es de riego (610,000 ha). Este tipo de agricultura familiar tiene una capitalización superior a la empresarial, pues dispone de $48.2 \%$ de la mecanización agrícola: $35.4 \%$ de los tractores, $36.5 \%$ de las bodegas, $30.4 \%$ de los establos, $30.9 \%$ de los empacadoras y $36.1 \%$ de los frigoríficos.

El CA 1997 no especifica los ingresos rurales en la agricultura. Un estudio que utiliza información de 1990 y de 1996 permite distinguir el ingreso medio en hogares empleados en la agricultura.

El ingreso medio mensual expresa poca distancia entre los ingresos de la unidad de agricultura de subsistencia y la familiar. Ello obliga a integrantes de la familia de ambas

Gráfica 2

Ingreso medio mensual en pesos chilenos 1991*

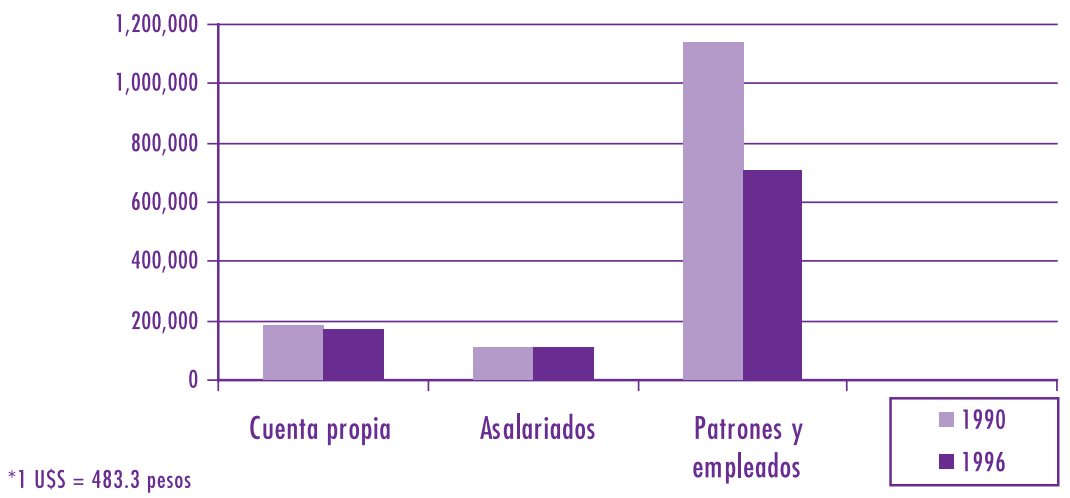

Fuente: Berdegué et al., 2004:39. 


\section{4}

MARCELLO CARMAGNANI

agriculturas a procurarse ingresos externos. Berdegué et al. sostienen que los ingresos rurales no agrícolas provienen del empleo en actividades que se desarrollan en los municipios o comunas más dinámicos, lo cual significa que la pluriactividad está más presente en los hogares rurales menos pobres. (Milicevic y Berdegué, 1998:10-17).

\section{Ecuador}

Según el Censo Nacional Agropecuario de 2000 (CNA 2000, www.sica.gov.ec), 40\% de la población ecuatoriana reside en el área rural y las dos terceras partes son productores agropecuarios. Estos últimos tienen un marcado carácter étnico y constituyen una parte importante de la estructura productiva rural en general y agrícola en particular. Son, por lo mismo, actores importantes en el cambio social ecuatoriano.

El CNA 2000 es seguramente uno de los más completos de América, pues contiene las cuatro dimensiones esenciales para definir la agricultura familiar: activos en tierra, trabajo y capital; acceso a los servicios; relación con el mercado, y el ingreso.

Cuadro 9

Tierra, trabajo, capital, servicios, comercialización e ingreso

\begin{tabular}{|c|c|c|c|c|c|c|c|c|c|c|c|c|c|}
\hline \multirow[t]{2}{*}{ Tierra } & \multicolumn{3}{|c|}{ Trabajo } & & \multicolumn{2}{|c|}{ Capital } & \multicolumn{3}{|c|}{ Servicios } & \multicolumn{2}{|c|}{ Comercializacion } & Ingreso & \multirow[t]{2}{*}{ Agric } \\
\hline & 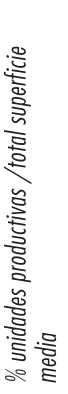 & 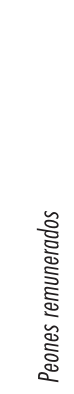 & 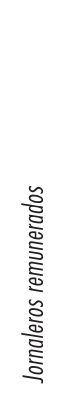 & 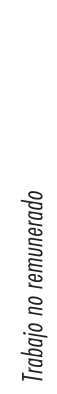 & 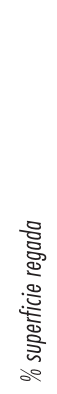 & 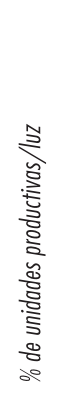 & 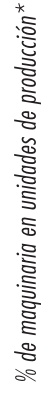 & 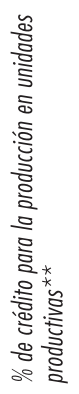 & 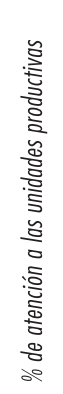 & 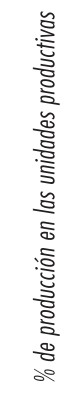 & 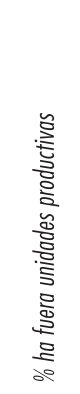 & 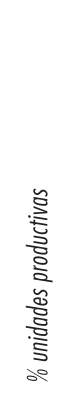 & \\
\hline-1 & 29.5 & 0.4 & 1.5 & 2.0 & 0.2 & 17.3 & * & ** & & & & & \\
\hline $1-5$ & 34.0 & 1.4 & 1,8 & 2.4 & 1.3 & 28.9 & 0. & 77.0 & 3.0 & 21.8 & $40 \ldots 5$ & 42.1 & 47.2 \\
\hline $5-10$ & 12.0 & 6.8 & 2.7 & 3.2 & 2.9 & 35.0 & 1.4 & 79.8 & 47.0 & 22.8 & 58.0 & 70.2 & 72.8 \\
\hline $10-20$ & 8.9 & 13.4 & 3,7 & 3.6 & 5.0 & 43.7 & 1.7 & 92.7 & 38.9 & 24.4 & 64.0 & 82.3 & 82.7 \\
\hline $20-50$ & 9,1 & 30.8 & 4.2 & 3.7 & 10.0 & 54.5 & 1.8 & 91.4 & 40.4 & 22.9 & 67.0 & 85.2 & 85.5 \\
\hline 50-100 & 4.1 & 65.0 & 4.2 & 4.7 & 22.8 & 61.0 & 2.1 & 89.8 & 50.4 & 23.9 & 65.7 & 84.5 & 84.3 \\
\hline+100 & 2.4 & 268.9 & 9.5 & 6.5 & 89.9 & 53.7 & 3.5 & 87.6 & 50.4 & 26.1 & 61.9 & 81.6 & 81.9 \\
\hline
\end{tabular}

* Maquinaria agropecuaria + equipo de procesamiento + equipo de transporte.

** Sistema de riego, estructuras y establos, semillas mejoradas, compra ganado.

\section{Desarrollo}


En un estudio relativo al programa de desarrollo rural para la sierra ecuatoriana se presentan los grupos de familia según el tamaño del predio: a) los que carecen de tierra y b) los que poseen más de 20 ha. De esta distinción se precisa que existe un flujo de trabajo muy fuerte de las familias con menos de una hectárea, tanto hacia las unidades productivas agrarias como hacia el sector no agrícola. A partir de los predios familiares con más de 5 ha, la venta de mano de obra para la agricultura como para el sector no agrícola se reduce notablemente: sólo 5.2\% de las familias trabaja en otros predios agrícolas y 6.2 labora en el sector no agrícola (De Janvry y Glikman, 1991).

El CAN 2000 expresa los cambios en la agricultura ecuatoriana que se han consolidado con el Programa de Desarrollo Tecnológico Agropecuario (PROTECA) inaugurado en 1987. Se deduce de los estudios que el mercado se ha convertido en el principal instrumento de asignación de la tierra y de otros activos en el sector agropecuario y que esta tendencia se ha reforzado cuando se estableció la ley de desarrollo agrario de 1994 (Jordan, 1996:120-127; Solo de Zaldívar, 2005).

El contexto de las transformaciones ocurridas en el mundo rural nos ayuda a reconstruir la forma que asume la agricultura familiar en Ecuador. Más de la mitad de las unidades de producción (63.5\%) tiene extensiones que no superan 1.4 ha, y sólo $6.5 \%$ de las unidades productivas supera las 65 ha. Los datos relativos a la dotación de tierra permiten observar que la mayor distancia en las superficies medias de las unidades productivas se da desde del estrato que fluctúa entre 50-100 ha.

$\mathrm{Si}$ bien todas las unidades productivas requieren contratar mano de obra no familiar, las explotaciones con menos de 5 ha tienden a contratar jornaleros —es decir, mano de obra no permanente_-, mientras que los predios de 5 a 10 hectáreas contratan peones y mano de obra permanente. En los estratos siguientes, a partir de 10-20 ha, la mano de obra permanente aumentó con mayor rapidez.

Si relacionamos tierra y trabajo, se puede señalar una diferencia entre las tres agriculturas: la de subsistencia comprende los estratos con una superficie media comprendida entre 0.4 y 1.4 ha; la familiar requiere un nivel mínimo de tierra de 6.8 ha; y el nivel mínimo de superficie en la agricultura empresarial es superior a las 65 ha.

Para precisar mejor el límite inferior y superior de la agricultura familiar, se debe relacionar tierra y trabajo con capital. Para ello un buen indicador puede ser la superficie regada, sólo que sorprende que tanto la agricultura familiar como la empresarial tienen una dotación similar de tierras de regadío alrededor de un tercio de la superficie total.

Lo mismo ocurre con el indicador del activo en capital porque tanto los establecimientos familiares como empresariales disponen de unidades similares de tractores (entre 1.1 y 1.4 unidades). El uso de energía eléctrica diferencia de nueva cuenta la 
agricultura de subsistencia de la familiar y empresarial. Así como la asistencia técnica recibida diferencia la agricultura de subsistencia y de la familiar. Esta última eleva su participación en el crédito para adquisición de insumos, mas no en crédito para incremento de capital fijo en maquinaria, equipo de procesamiento y equipo de trabajo.

La agricultura familiar es la que además presenta una mayor articulación con el mercado. En efecto, más de $60 \%$ de las explotaciones con una extensión media entre 6.8 y 30.8 ha tiene capacidad para comercializar su producción fuera del predio.

El indicador relativo al ingreso nos precisa el elemento en que venimos insistiendo: la agricultura familiar es la que obtiene más de $80 \%$ de sus ingresos de la actividad agrícola. En cambio, la agricultura de subsistencia requiere que sus miembros se empleen como jornaleros y peones fuera del predio familiar para reunir un ingreso mínimo. Justamente por ello el quintil de ingreso más bajo lo obtiene de varias fuentes: $69 \%$ de la producción de su finca, $6 \%$ del trabajo asalariado; $22 \%$ del trabajo no agrícola o de actividades artesanales y $3 \%$ de las transferencias familiares y remesas. Los tres quintiles siguientes, los de agricultura familiar, obtienen $46 \%$ de sus ingresos de la actividad agrícola, 14\% del trabajo asalariado agrícola, 37\% de las actividades no agrícolas y 3-4\% de remesas y transferencias familiares (Lanjouw, 1999; Martínez, 2000; Elbers y Lanjouw, 2000:134-135).

Con estos elementos se puede afirmar que la agricultura familiar ecuatoriana se compone de 250,000 productores, $30 \%$ del total, y éstos disponen de 4 millones de ha $(33 \%$ de la superficie agropecuaria total). Se trata además de una agricultura articulada con el mercado, con el mercado de la tierra, con el trabajo agrícola, rural y urbano, con el mercado de capitales de las instituciones de crédito y con el mercado de bienes.

\section{Nicaragua}

El Censo Nacional Agropecuario de Nicaragua 2001, al igual que otros realizados entre 1996 y 2005 (CENAGRO, 2001 www.inec.gob.ni), forma parte del programa mundial de censos promovidos por la FAO, lo que explica el que la unidad estadística de investigación se encuentre bien definida. En este caso, "explotación" es "todo terreno que se utiliza total o parcialmente para la producción de agricultura, ganadería o una combinación de ambas, que se explota como unidad técnica y económica al interior de un municipio, sin consideración del tamaño, régimen de tenencia ni condición jurídica" (Conceptos y definiciones básicas, 2002).

La superficie agropecuaria nicaragüense representa 8.9 millones de manzanas (6.3 $\mathrm{mn}$ de ha) con un marcado predominio de los productores individuales $(98.6 \%)$, de 
los cuales sólo 180,761 (68\%) tienen pleno derecho de propiedad, mientras el resto tiene títulos imperfectos, ya sea por falta de escritura pública, por estar en proceso de legalización, o por contar con títulos de posesión otorgados desde la reforma agraria.

Vale la pena añadir que Nicaragua es el segundo país latinoamericano que padece mayor inseguridad alimentaria, donde el sector rural es el más afectado y donde la población rural utiliza la mayor parte de sus ingresos en la adquisición de alimentos (FAO, 2000).

Según un estudio de la CEPAL con información de 1997, precedente al CENAGRO 2001, la distribución de la tierra por estrato presenta las siguientes divisiones:

Gráfica 3

Distribución de la tierra por estratos, 1997

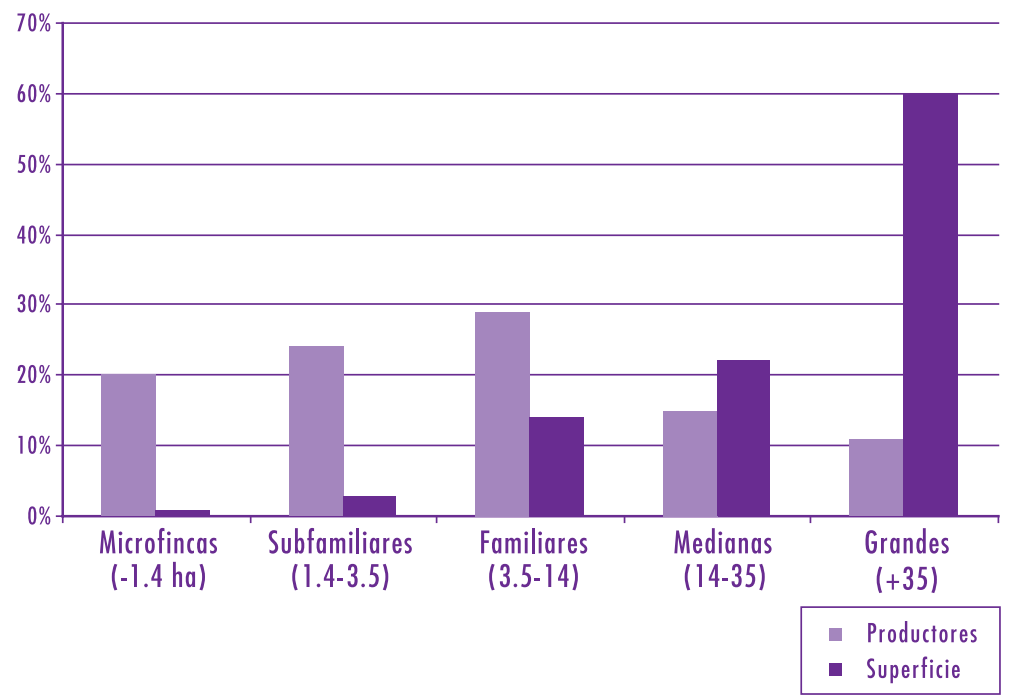

Fuente: CEPAL 2001: 50-51

Sin entrar en el mérito en la tipología propuesta, tenemos que la agricultura familiar representa $29 \%$ de los productores y $14 \%$ de la superficie agropecuaria.

La información censal nos dice que hay $33.2 \%$ de unidades productivas $(65,978)$ que poseen menos de 5 manzanas ( $3.5 \mathrm{ha}$ ) que cubren $1.8 \%$ de la superficie agropecuaria (157,570 manzanas), y una superficie media de 2.4 manzanas (1.7 ha). Ello significa que hay una diferencia de 197,000 manzanas (139,000 ha) entre la superficie de las microfincas y subfamiliares estimada por CEPAL y la que estimamos con base en el CENAGRO 2001. 
Cuadro 10

Tierra, trabajo, capital y servicios

\begin{tabular}{|c|c|c|c|c|c|c|c|}
\hline \multirow{2}{*}{$\frac{\text { Estratos }}{\left.\text { (Manzanas }^{\star}\right)}$} & \multicolumn{2}{|c|}{ Tierra } & \multirow{2}{*}{$\begin{array}{c}\text { Trabajo } \\
\text { Unidades } \\
x \text { unidades } \\
\text { de producción }\end{array}$} & \multirow{2}{*}{$\begin{array}{c}\text { Capital } \\
\text { \%nidades } \\
\text { productivas } \\
\text { regadas }\end{array}$} & \multicolumn{3}{|c|}{ Servicios } \\
\hline & $\begin{array}{l}\text { \% unidades } \\
\text { productivas / total }\end{array}$ & $\begin{array}{l}\text { Superficie } \\
\text { media }\end{array}$ & & & $\begin{array}{l}\text { \% tractores en } \\
\text { unidades } \\
\text { productivas }\end{array}$ & $\begin{array}{l}\% \text { créditos } \\
\text { unidades } \\
\text { productivas }\end{array}$ & $\begin{array}{c}\text { \% unidades } \\
\text { productivas } \\
\text { con asistencia } \\
\text { técnica }\end{array}$ \\
\hline -1- & 9.1 & 0.7 & 1.8 & 1.3 & 1.7 & 8.1 & 9.1 \\
\hline $1-5$ & 24.1 & 3.0 & 3.8 & 1.5 & 3.8 & 17.6 & 15.4 \\
\hline $5-10$ & 14.3 & 7.9 & 5.0 & 1.1 & 4.2 & 19.3 & 18.4 \\
\hline $10-20$ & 13.5 & 15.8 & 5.7 & 0.7 & 3.7 & 17.7 & 17.5 \\
\hline $20-50$ & 19.5 & 36.2 & 6.5 & 0.5 & 2.7 & 13.4 & 14.5 \\
\hline $50-100$ & 10.8 & 77.2 & 7.7 & 0.5 & 2.9 & 10.9 & 13.0 \\
\hline+100 & 8.7 & 288.1 & 17.7 & 2.2 & 7.6 & 11.8 & 15.5 \\
\hline
\end{tabular}

* 1 manzana $=0.7050$ ha.

Fuente: CENAGRO 2001.

La marginalidad de las unidades productivas con una superficie media de 1.7 ha se comprueba con el indicador de mano de obra remunerada y por la escasa presencia de tractores, así como por la reducida capacidad de tener acceso a crédito, asistencia técnica y capacitación.

En los estratos siguientes observamos que las unidades productivas con una superficie media entre 7.9 y 36.2 manzanas (5.6-25 ha) tienen mayor punto de contacto relativo al uso de mano de obra no familiar y al acceso a servicios como crédito, asistencia técnica y capacitación. De hecho, observamos que las unidades productivas con una superficie de entre 5.6 y 25 ha se distinguen por ser de agricultura más intensiva y más capitalizada.

Un reciente estudio sobre las cooperativas de producción presenta, a partir de una muestra de 476 unidades productivas, un perfil interesante de la agricultura familiar:

Cuadro 11

\begin{tabular}{ll}
\hline Tamaño de la familia & 6.7 \\
Adultos (+ de 8 años) & 5.2 \\
Capital en tierras: & 21.3 manzanas \\
Id en animales: $\left(\mathrm{n}^{\circ}\right)$ & 9.3 \\
Equipos agrícolas $\left(\mathrm{n}^{\circ}\right)$ & 5.9 \\
Ingreso no agrícola & $50 \%$ \\
\hline
\end{tabular}

Fuente: Rubén y Lerman 2005:37.

\section{Desarrollo}


Las unidades productivas con una extensión media comprendida entre 77.2 y 288.1 manzanas (54.4-203 ha) son las de menor inversión en riego, tractores, y las que más recurren al crédito y a la asistencia técnica. Los establecimientos de superficie mayor a 50 ha explotan la tierra en modo extensivo pues tienen escasa inversión en tractores, cosechadoras, generadores eléctricos, bombas de riego (CENAGRO, 2001:cuadro 56). Si bien son unidades productoras de bienes agrícolas, sólo 15.8\% utiliza semilla certificada o mejorada, utilizan la semilla criolla autoproducida. Además el uso de fertilizantes, abonos orgánicos, insecticidas y herbicidas es mínimo (CENAGRO, 2001, cuadro 44)

Una muestra representativa del ingreso neto rural ayuda a precisar los elementos ofrecidos. Por ingreso rural se entiende aquel que se obtiene sustrayendo al valor total de la producción, los gastos en insumos y salarios por mano de obra no familiar.

Cuadro 12

Fuentes de ingreso de las familias rurales 1999

\begin{tabular}{rcccccc}
\hline $\begin{array}{c}\text { Tamaño } \\
\text { Predio }\end{array}$ & $\begin{array}{c}\text { Grupo } \\
\text { Ingreso }\end{array}$ & $\begin{array}{c}\text { Ingreso } \\
\text { Predio }\end{array}$ & $\begin{array}{c}\text { Ingreso } \\
\text { Salario agrícola }\end{array}$ & $\begin{array}{c}\text { Ingreso } \\
\text { Salario no agrícola }\end{array}$ & $\begin{array}{c}\text { Empleo } \\
\text { Cuenta propia }\end{array}$ & $\begin{array}{c}\text { Otros } \\
\text { Ingresos }\end{array}$ \\
\hline-5 & Mínimo & 53 & 24 & 15 & -1 & 9 \\
$5-20$ & Segundo & 41 & 29 & 19 & 4 & 8 \\
$20-50$ & Tercero & 35 & 24 & 26 & 6 & 14 \\
+50 & Máximo & 33 & 13 & 34 & & 7 \\
\hline
\end{tabular}

Fuente: Corral y Reardón, 2001:61.

Corral y Reardón muestran que 49\% de los hogares rurales sólo percibe un ingreso agrícola, $6 \%$ sólo un ingreso no agrícola y $41 \%$ de los hogares tienen ambos. Del cuadro 12 se nota que el estrato de hogares entre 5 y 50 manzanas obtiene 51-64\% de su ingreso de la actividad de su predio agrícola. Según el CENAGRO 2001 , éste es el estrato que contrata mano de obra y al mismo tiempo cede trabajo. $\mathrm{Si}$ al ingreso agregamos el ingreso derivado del salario agrícola y no agrícola que cubre el costo del asalariado contratado encontramos que es posible que quede en la unidad familiar un excedente derivado del diferencial salarial entre sector agrícola y no agrícola. 
La información relativa al ingreso nos permite precisar que la agricultura familiar se ubica en los establecimientos que oscilan entre 5.6 y 50 ha. Así, la agricultura familiar se caracteriza por componerse de múltiples actividades que permiten integrar los ingresos netos agrícolas con los obtenidos del empleo rural y no rural y de otras actividades.

\section{México}

El último Censo Agrícola Ganadero (CAG 1991, www.inegi.gob.mx) se realizó a partir de la unidad de producción definida como "el conjunto formado por los predios, terrenos y parcelas con o sin actividad agrícola, ganadera o forestal que se encuentren en un mismo municipio; los animales criados por su carne, leche, hueso, piel, miel o para trabajo que posean; así como los elementos de producción disponibles para estas actividades, siempre que en el año agrícola todo esto se haya manejado bajo una misma administración" (Sinópsis estadística, 2003).

Las variables capturadas para definir la unidad de producción privada como la ejidal o de propiedad social — resultante de la reforma agraria llevada a cabo en el siglo pasado - recogen las recomendaciones internacionales de la FAO. La información se articula en 12 partes: cuatro sobre producción, una sobre la organización de las unidades productivas, una sobre la mano de obra, dos sobre instalaciones, maquinarias y una sobre el destino de la producción. Desgraciadamente tanto los volúmenes publicados como el CD no desagregan la información por estrato, lo cual impide el reconocimiento del segmento de la agricultura familiar.

El más reciente Censo Ejidal 2001 presenta problemas similares, pues la información relativa a las actividades, al capital en instalaciones y maquinaria, a la infraestructura y los servicios, la proporciona el municipio y el estado sin distinción de superficie por la unidad productiva (Censo Ejidal 2001, www.inegi.gob.mx).

La única información útil para el reconocimiento de la agricultura familiar se encuentra en INEGI y es el cuadro donde se presenta el empleo en las unidades productivas privadas y ejidales, y se distingue el empleo no remunerado familiar y el empleo no familiar, así como el eventual y permanente remunerado.

Excepto el predio de superficie media de 1.1 ha, el trabajo proviene en esencia de la familia y de familiares (allegados o entenados) no remunerados que aquí llamo familia extendida. Este mix de trabajo familiar y de la familia extendida no remunerado es una constante en las unidades productivas que fluctúan entre 3.6 y 72.8 ha.

A partir del predio de superficie media de 3.6 ha se recurre a mano de obra remunerada eventual. La encontramos en unidades productivas de 3.6 a 10.6 ha, más de 
Cuadro 13

Tierra, trabajo y capital. Unidades productivas totales y ejidades

\begin{tabular}{|c|c|c|c|c|c|c|c|c|c|c|c|c|c|c|}
\hline \multirow[t]{3}{*}{ Total } & \multicolumn{3}{|c|}{ Tierra } & \multicolumn{4}{|c|}{ Trabajo } & \multirow{3}{*}{ 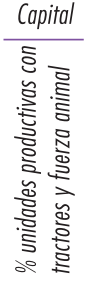 } & \multirow[t]{3}{*}{ Eiidal } & \multirow{3}{*}{ 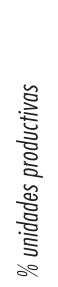 } & \multicolumn{4}{|c|}{ Trabajo } \\
\hline & \multirow{2}{*}{ 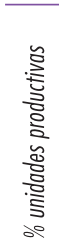 } & \multirow{2}{*}{ 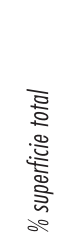 } & \multirow{2}{*}{ 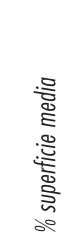 } & \multicolumn{2}{|c|}{$\begin{array}{c}\text { No } \\
\text { remunerado }\end{array}$} & \multicolumn{2}{|c|}{ Remunerado } & & & & \multicolumn{2}{|c|}{$\begin{array}{c}\text { No } \\
\text { remunerado }\end{array}$} & \multicolumn{2}{|c|}{ Remunerado } \\
\hline & & & & $\frac{\text { so }}{\frac{\text { s. }}{2}}$ & 氪 & $\begin{array}{l}\overline{\text { ș }} \\
\text { 总 }\end{array}$ & 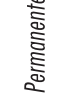 & & & & 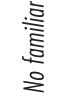 & 言 & $\begin{array}{l}\overline{\text { s. }} \\
\text { 总 }\end{array}$ & \\
\hline-2 & 33.9 & 1.6 & 1.1 & 0.4 & 2.2 & 0.4 & 0.03 & 25 & -2 & 31.2 & 0.07 & 2.2 & 0.4 & 0.02 \\
\hline $2-5$ & 23.9 & 3.8 & 3.6 & 2.3 & 2.2 & 0.5 & 0.05 & 36 & $2-5$ & 28.0 & 0.07 & 2.2 & 0.5 & 0.04 \\
\hline $10-20$ & 30.8 & 13.8 & 10.6 & 2.2 & 2.2 & 0.5 & 0.09 & 49 & $5-20$ & 35.9 & 0.07 & 2.1 & 0.5 & 0.07 \\
\hline $20-50$ & 5.4 & 7.2 & 31.5 & 2.2 & 2.1 & 0.7 & 0.28 & 45 & 20-50 & 3.9 & 0.07 & 2.0 & 0.5 & 0.10 \\
\hline 50-100 & 1.8 & 5.7 & 72.8 & 2.9 & 2.1 & 1.1 & 0.73 & 50 & $50-100$ & 0.6 & 0.08 & 2.1 & 0.6 & 0.17 \\
\hline 1000 & 1.8 & 22.4 & 273.7 & 2.2 & 2.1 & 1.5 & 1.31 & 55 & & & & & & \\
\hline+1000 & 2.4 & 45.5 & 4442.1 & 1.8 & 1.7 & 1.6 & 2.16 & 67 & +100 & 0.4 & 0.12 & 2.6 & 0.8 & 0.29 \\
\hline
\end{tabular}

Fuente: CAG 1991; de Grammont, 2000:77.

las unidades productivas entre 31.4 y 72.8 ha. Sólo en los predios de una extensión superior a las 72.8 ha es significativa la mano de obra permanente.

La relación tierra-trabajo nos permite dividir el mundo agropecuario mexicano en tres conjuntos: el de las unidades que fluctúan entre 3.6 y 72.7 ha; el de unidades que fluctúan entre 72.7 y 273.7 ha, y el de las unidades que tienen más de 273.7 ha. Esta distinción se podría precisar mejor si dispusiéramos de información similar proveniente del Censo Ejidal 2001.

La información acerca de la importancia de la mano de obra no remunerada no familiar (2.2-2.3 unidades por predio) para los predios, en general, contrasta con la escasa importancia que tiene este tipo de mano de obra en los ejidos de 0.07-0.12 unidades por predio. La mano de obra remunerada aún es más reducida en los ejidos que en los predios privados y mixtos. En los ejidos el trabajo familiar es el principal y casi único sustento de la explotación.

Un excelente estudio, que utiliza encuestas de la Secretaría de Agricultura y CEPAL de 1990 y 1994, nos ayuda a visualizar mejor el sector ejidal. En este estudio, el activo tierra es medido en equivalentes nacionales de tierra de temporal o secano (ENTT). 
42

MARCELLO CARMAGNANI

42

Cuadro 14

Distribución de la tierra ejidal por tipos de predios y tipos de uso, 1994

\begin{tabular}{rrrccc}
\hline & \% superficie total & Tamaño & Tierra de cultivo & Área irrigada \% & $\begin{array}{c}\text { Distribución de predios } \\
\text { irrigados-áreas irrigadas }\end{array}$ \\
\hline 2 & 22.8 & 1.2 & 99.9 & 15.0 & 89.9 \\
5 & 34.4 & 3.3 & 93.3 & 15.00 & 75.7 \\
10 & 19.2 & 7.2 & 79.7 & 30.3 & 81.4 \\
18 & 16.5 & 13.9 & 60.4 & 41.4 & 84.2 \\
18 & 7.1 & 35.4 & 57.4 & 32.6 & 84.6 \\
\hline
\end{tabular}

Fuente: Gordillo, De Janvry y Sadoulet 1999:50.

Los estratos de tierra ejidal con el porcentaje más elevado de tierra cultivada son los que fluctúan entre menos de 2 ha ENTT y hasta las 10 ha ENTT. Sin embargo, las unidades ejidales que presentan una mejor relación entre superficie irrigada y distribución entre predios irrigados y área irrigada son las unidades ejidales entre 5 y18 ha ENTT. El análisis de Gordillo, De Janvry y Sandoulet ayuda a entender la evidencia censal relativa a la escasa aportación de trabajo remunerado y la reducida presencia de mano de obra remunerada en la actividad de la unidad ejidal. Se puede afirmar así que el sector ejidal se caracteriza por una relativa abundancia de trabajo debido al tamaño del núcleo familiar en los predios inferiores a 3.8 ha. De allí que el trabajo que desempeñan los miembros de las familias, tanto al interior del predio como fuera de él, se caracterice por una notable flexibilidad. Ello significa que en el arco de un año agrícola pueden moverse desde la unidad productiva hacia otras actividades extraprediales en el área cercana hacia las ciudades aledañas e incluso emigrar para regresar en los momentos que su trabajo es fundamental para el desempeño productivo del predio (siembra y cosecha).

Las encuestas ejidales muestran que $45 \%$ de los productores con predios más grandes (10.1 ha ENTT) y más tierra de riego (0.98 ha) siembra más maíz, utiliza más semilla mejorada (50\%), productos químicos (74\%) y fertilizantes (79\%) que el resto de los ejidatarios. El resultado es que obtienen rendimientos mucho mayores en las tierras de riego (3.8 t/ha para el maíz) y tienen menos miembros de la familia que participan en el mercado de trabajo o que deben emigrar. En dichas unidades ejidales existe una buena asociación entre el tamaño del predio y la modernización de las actividades productivas, pues todas las actividades específicamente agrícolas declinan y la mayor producción de maíz la utilizan para la generación del ganado 
que va al mercado. También observamos que recurren menos al crédito asistencial del gobierno (PRONASOL) y más al crédito de los bancos comerciales que los ayuda a incrementar la cría de ganado y que les redunda en mayores ingresos (Gordillo, De Janvry y Sadoulet 1999:154-168).

La relación entre los activos tierra, trabajo y capital muestra que la diferencia y la flexibilidad de estrategias son las principales características de la agricultura familiar mexicana. Esto nos lleva a pensar que el punto límite inferior de este tipo de agricultura se coloque en las unidades productivas de más de 10 ha ENTT que, según los datos del CAG 1991, afecta el estrato de las unidades productivas entre 10 y 20 ha.

En el estrato que fluctúa entre 10 y 20 ha se observa el mayor empleo de mano de obra remunerada y el mayor uso de tractores; características que comparten los dos estratos siguientes: los predios con 20-50 ha y 50-100 ha. Ello significa que la superficie media de la unidad productiva de agricultura familiar, que permite diferenciarla de la agricultura de subsistencia así como de la agricultura empresarial, es la que fluctúa entre 10.6 y 72.8 ha. En suma, el tamaño de la agricultura familiar es de 1.5 millones de unidades productivas, equivalente a $37.9 \%$ del total. De esos 1.5 millones de productores familiares, un millón se encuentra en el sector ejidal, lo cual significa que $66.6 \%$ de los agricultores familiares son beneficiarios de la reforma agraria del siglo pasado. No es casual entonces que los subsidios de PROCAMPO logren generar un efecto multiplicador del ingreso familiar (Cord y Wodon, 2001).

El Censo Agrario 1991 registra que sólo 19.2\% de las unidades productivas $(744,400)$ recibió créditos de agencias gubernamentales y de la banca comercial, lo que indica que gran parte de la agricultura familiar se topa con un obstáculo significativo para su desempeño. En efecto, $55.5 \%$ de las unidades de la agricultura de subsistencia destina la casi totalidad de las cosechas al autoconsumo, mientras que — según CAG 1991- la unidad productiva familiar autoconsume $31.4 \%$ de su producción. A diferencia de la agricultura de subsistencia, el autoconsumo en la agricultura familiar incluye una parte de bienes, que representa insumos para los bienes que comercializa la unidad.

Podemos observar el ingreso agropecuario y no agropecuario en las unidades de producción mediante la información proveniente de una encuesta nacional del sector ejidal realizada en 1997 por la Secretaria de la Reforma Agraria y el Banco Mundial, y que ha sido estudiada por De Janvry y Sadoulet (2004). 
Cuadro 15

Participación en el ingreso en el sector ejidal desglosado por superficie del predio (ha ENTT) 1997

\begin{tabular}{lrrrrr}
\hline \multicolumn{5}{c}{ Hectáreas } \\
\hline & -2 & $2-5$ & $5-10$ & $10-18$ & $10-18$ \\
Ingreso total (\$Méx) & 12,474 & 17,314 & 28,368 & 30,564 & 44,255 \\
Ingreso agrícola \$ & 2,855 & 4,869 & 11,859 & 15,377 & 27,454 \\
Ingreso no agrícola \$ & 9,616 & 12,444 & 16,512 & 15,187 & 16,801 \\
Ingreso agrícola \% & 5.1 & 22.9 & 41.8 & 50.3 & 62 \\
Ingreso no agrícola \% & 54.9 & 77.1 & 58.2 & 49.7 & 38 \\
Salarios & 24.6 & 40,3 & 30.4 & 18.9 & 11.1 \\
Salarios agrícolas & 4.8 & 10 & 4.2 & 5.7 & 1.2 \\
Salarios no agrícolas & 19.9 & 30.3 & 26.2 & 12.5 & 9.9 \\
Trabajo x cuenta propia & 9.4 & 17.1 & 4.6 & 12.1 & 6.8 \\
Remesas & 6.5 & 2.6 & 8.9 & 6 & 6 \\
Otros & 14.4 & 17.1 & 14.3 & 13.3 & 14.1 \\
\hline
\end{tabular}

Fuente: de Janvry y Sadoulet 2004:10

Por medio del ingreso se observa que los predios ejidales del estrato 5-10 ha ENTT comienzan por asumir características de agricultura familiar. Y que a partir de ese estrato el ingreso agrícola se vuelve relevante para la reproducción familiar y para la generación de insumos imputables a la producción agrícola y no agrícola que se venden en el predio o fuera del mismo. Los predios inferiores a 5 ha ENTT confirman que el ingreso agrícola sirve esencialmente para la simple reproducción familiar y a lo más la de sus entenados. Sin embargo, esta agricultura ejidal de subsistencia no debe ser subestimada porque garantiza un sustento mínimo a un sector de la población que puede desempeñar trabajos rurales (en especial, en los predios privados) y no rurales aun cuando debe aceptar salarios muy bajos. Precisamente por ello se nota la propensión a emigrar o activar trabajos por cuenta propia. La viabilidad de los predios ejidales de menos de 5 ha ENTT depende exclusivamente de la capacidad de articularse con el sector rural no agrícola. La dependencia del salario no agrícola y de las remesas es elevada: $32.9 \%$ para los predios de menos de 2 ha ENTT y $34.8 \%$ para los predios entre 2 y 5 ha de secano.

La viabilidad de la agricultura familiar ejidal depende así de la capacidad de organizarse en múltiples actividades; es decir, en dar vida a estrategias que combinen el ingreso agrícola — superior a 50\% de los ingresos totales— con el ingreso 
no agrícola que es principalmente extrarrural. Debe darse la debida importancia al hecho de que el valor absoluto de los ingresos provenientes de las actividades fuera del predio aumenta con el tamaño de la explotación. Ello significa que en los predios de 10 o más hectáreas de secano se logra ahorrar una parte del ingreso total para destinarlo a la adquisición de bienes de consumo durables, a inversiones productivas o a la educación de sus hijos.

De Janvry y Sadoulet (2004:113) sostienen que en el desglose de la desigualdad total de ingresos por fuentes se comprueba que la agricultura es la que más contribuye a la desigualdad de los ingresos, mientras un papel menor lo tiene el ingreso por concepto de salario no agrícola. Las otras fuentes de ingreso, incluyendo las remesas, sólo contribuyen a la desigualdad de los ingresos de forma marginal. La fuente de ingreso más igualitaria es el trabajo asalariado agrícola, fácil de obtener y poco remunerado, seguida del trabajo por cuenta propia que tiene un alto nivel de dualidad, que también incluye muchas actividades de fácil acceso y baja remuneración. Probablemente el nivel igualitario del trabajo asalariado agrícola y del trabajo por cuenta propia es más aparente que real, pues — como ya se dijo— se sustenta en la capacidad del predio de proporcionar el autoconsumo, lo cual significa que la presión laboral sobre los miembros de la familia y de los eventuales entenados tiende no sólo a crecer, sino a reforzar la autoridad coercitiva del jefe de familia.

A partir de los primeros años de la década de los noventa la actividad no agrícola de los ejidatarios se acelera; al día de hoy parece haberse convertido en la principal, debido a la dificultad de arrendar tierras. Ello vuelve imposible aumentar los cultivos (Lanjouw, 2001).

Una encuesta de 1994 sobre el ingreso de 508 hogares con un total de 3,671 personas (7.2 habitantes por hogar) ilustra las dificultades de los ingresos de los predios con menos de 5 ha. La encuesta coincide en muchos aspectos con la información de los ingresos en el ámbito nacional. En especial, nos dice que la participación del ingreso no agropecuario en el total es de $87.8 \%$ y que en este ingreso tiene una enorme importancia los salarios conseguidos en los escenarios local, regional y nacional, así como las remesas de migrantes (14.8\%), Nos dice además que poco ayuda la modernización, pues las formas de reciprocidad propias de la comunidad campesina están desapareciendo, debido a que contribuyen apenas con 1.6\% del ingreso total.

El análisis de Yúnez-Naude, Taylor y Becerril (2000:105-107 y 128-129) nos permite agregar algunos elementos sobre la integración al mercado de los predios. El análisis de multiplicadores, basado en matrices de contabilidad social de cada uno de los 14 pueblos encuestados, muestra que el potencial del impacto del cambio es 
elevado y que dependen de la integración al mercado, es decir, de las vinculaciones por el lado de la demanda, entre lo agrícola y lo no agrícola. Además de que vínculos entre el sector agrícola y los otros sectores económicos dependen mucho de la oferta agropecuaria.

Una encuesta basada en 285 productores de seis municipios de la región de Querétaro y en la fértil área del Bajío nos muestra la presencia de un estrato de arrendatarios con una media de tierras rentadas de 12.4 ha. Se trata de un segmento de agricultura familiar porque tiene una serie de activos nuevos e importantes (tractores, ganados y utilización de semilla mejorada) con el resultado de que su ingreso medio es similar al de las unidades productivas con una superficie comprendida entre 5 y 10 ha. Al mismo tiempo, comparten la misma característica de los productores con más de 5 ha: la mitad de su ingreso proviene de la agricultura. En cambio, el desempeño de los predios de 1 a 3 ha es similar al registrado en la encuesta de 1994, es decir, el de una agricultura de subsistencia. (Rello y Morales, 1998). Sin embargo, a diferencia de lo ilustrado por Yúnez et al. (2000), tienen una mayor proporción de tractores, ganado y utilizan semilla mejorada. Precisamente su producción se realiza en una de las mejores áreas agrícolas de México y sus ingresos son superiores a la media nacional.

En síntesis, si bien se visualizan en la agricultura familiar mexicana algunos de los rasgos de las unidades con más de 5 ha, es en los predios con una extensión superior a las 10 ha donde adquieren plenamente las características propias de lo que se define como agricultura familiar: contar con una discreta dotación de capital físico, poder integrar el ingreso agrícola con otros ingresos y poseer capacidad innovativa.

La lógica productiva de la agricultura familiar reside en su capacidad para complementar el trabajo familiar con mano de obra asalariada, y a su vez el poder ofrecerse en el mercado de trabajo para actividades no necesariamente rurales les permite generar ingresos superiores a los salarios que pagan el trabajo agrícola. La permutación del trabajo activo confiere gran dinamicidad a la agricultura familiar y permite incluso que unidades con una reducida dotación de tierras puedan superar el umbral de la agricultura de subsistencia.

El dinamismo de la agricultura familiar mexicana nace también de su capacidad para integrarse al mercado de bienes derivado del vínculo que ocurre entre el sector agropecuario y no agropecuario en el ámbito de la demanda y de la oferta de sus bienes a otros sectores de la economía real. Así se puede entender que la agricultura familiar hubiera conocido una expansión de la unidad productiva de 15 a 36\%, en el periodo censal 1970-1991. 


\section{Conclusión: la categoría agricultura familiar}

El análisis de las diferentes experiencias nacionales a la luz de las hipótesis presentadas en el primer párrafo de este artículo permite elaborar una categoría de agricultura familiar que tome en cuenta todos los activos disponibles de las diferentes familias en el agro. En efecto, los activos tangibles e intangibles forman un conjunto con las características del capital social. Es decir, representa un recurso específico y permanente de la acción que no está depositada "ni en los individuos ni en los medios de producción" y es intrínseco "a la estructura de relación entre dos o más personas" (Coleman, 1998).

Para procesar los elementos básicos de la agricultura familiar de determinadas experiencias nacionales aclaro que al no disponer de información censal adecuada es imposible presentar, como habría sido mi deseo, una definición más elaborada de la

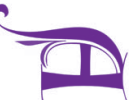
categoría agricultura familiar para las diferentes áreas del subcontinente. Las hojas de encuesta de los censos agropecuarios prometen proporcionar todas las variables para ilustrar en términos comparados la agricultura familiar en América Latina. Sin embargo, los datos que encontramos no permiten distinguir cosas tan elementales como el trabajo, el tamaño del predio y las vinculaciones con el mercado. En consecuencia, sólo puedo exponer las características generales para toda el área latinoamericana.

Los vectores identificados de la agricultura familiar revelan que los estudios acerca de los ingresos rurales no agrícolas terminan por reconocer sólo la capacidad de conjugar el ingreso proveniente de actividades agrícolas con el ingreso de actividades no agrícolas. Sin embargo, esta correlación proporciona información importante, pues permite definir la centralidad al trabajo. Me refiero a poder identificar el trabajo como el detonador de las decisiones que adoptan los miembros de la familia al formular sus estrategias. Las estrategias que desarrollan son flexibles pues deben adecuarse tanto a los cambios que ocurren en seno de la familia y en las redes territoriales, así como a los periodos de alta y baja de los precios relativos agrícolas.

La diferencia que emerge entre la agricultura familiar y la de subsistencia no se encuentra en una lógica distinta de las familias. Radica en que la agricultura familiar privilegia el trabajo en el predio y tiene por tanto una relación inconstante con las actividades externas a la unidad agrícola, mientras la agricultura de subsistencia debe mantener una relación constante con las actividades rurales y urbanas para subsistir.

Las decisiones que adoptan los agricultores familiares pretenden potenciar el predio, lo cual confiere a esta forma de agricultura la característica de desarrollar múltiples actividades. Aceptado lo anterior podemos superar la idea recurrente acerca de que la pluralidad de actividades no es exclusivamente para diversificar los ingresos 
(Mora y Sumpsi, 2004:25-27). En cambio, como muestran las distintas variables, la diversificación de actividades tiene qué ver con la capacidad de integrar insumos autoproducidos con insumos de origen industrial y con la capacidad de activarse para obtener los servicios necesarios que garanticen la pluriactividad en el ámbito de la producción. En suma, las múltiples actividades no son otra cosa que el resultado de las estrategias adoptadas por los agricultores familiares. En efecto, de los censos emerge que la agricultura familiar produce algunos bienes especializados para la industria (soja, colza, por ejemplo) pero genera también productos diversos (hortalizas, frutas, etcétera).

La pluriactividad se presenta en relación con la extensión del predio y con la dotación de capital bajo forma de insumos, maquinarias, edificios. El tamaño del predio varía según los países y los tipos de tierra, cultivos etcétera; es de esperarse que los próximos censos y encuestas agrarias rescaten las condicionantes como la geografía, el clima, los pisos ecológicos. No obstante, se identifica una diferencia entre la superficie media de tamaño del predio que garantiza el mejor desempeño agrícola. La disimilitud entre la superficie media mínima y la superficie mínima óptima es entre 1:2 y 1:3. Ello significa que si en Brasil la superficie media mínima es de 10.6 ha, la superficie mínima óptima es de 31 ha. Sin embargo, no basta sólo eso, el nivel de capitalización de las unidades productivas —el empleo del capital aumentado de la tasa de interés - incide en la dimensión del predio y su desempeño. La media antes citada es baja en dos países (Ecuador y Nicaragua), apenas suficiente en cuatro países (Brasil, Uruguay, Argentina y México) y suficiente en Chile.

La disponibilidad de tierra y capital ilustra que la estrategia de integrar activos favorece la productividad de la agricultura familiar. La adquisición de insumos industriales (fertilizantes, herbicidas) o la construcción de canales de regadío requieren poco capital contra una creciente incorporación de trabajo; ello aun en periodos de poca actividad agrícola. La intensidad del trabajo entonces es el dato fundamental de la agricultura familiar.

Las magnitudes relativas a la distancia ilustran el desnivel que hay entre las formas de agricultura así como al interior de la agricultura familiar. Los casos nacionales muestran que la distancia es notable entre la agricultura familiar y la empresarial, por el tamaño reducido de la parcela y el raquítico capital invertido en los predios familiares, mientras la agricultura empresarial usa sólo el factor tierra.

La distancia entre predios pertenecientes a la agricultura familiar no depende tanto del tamaño del establecimiento, sino de las magnitudes en la relación trabajo, tierra y capital, así como la localización geográfica, del costo del transporte y de la 


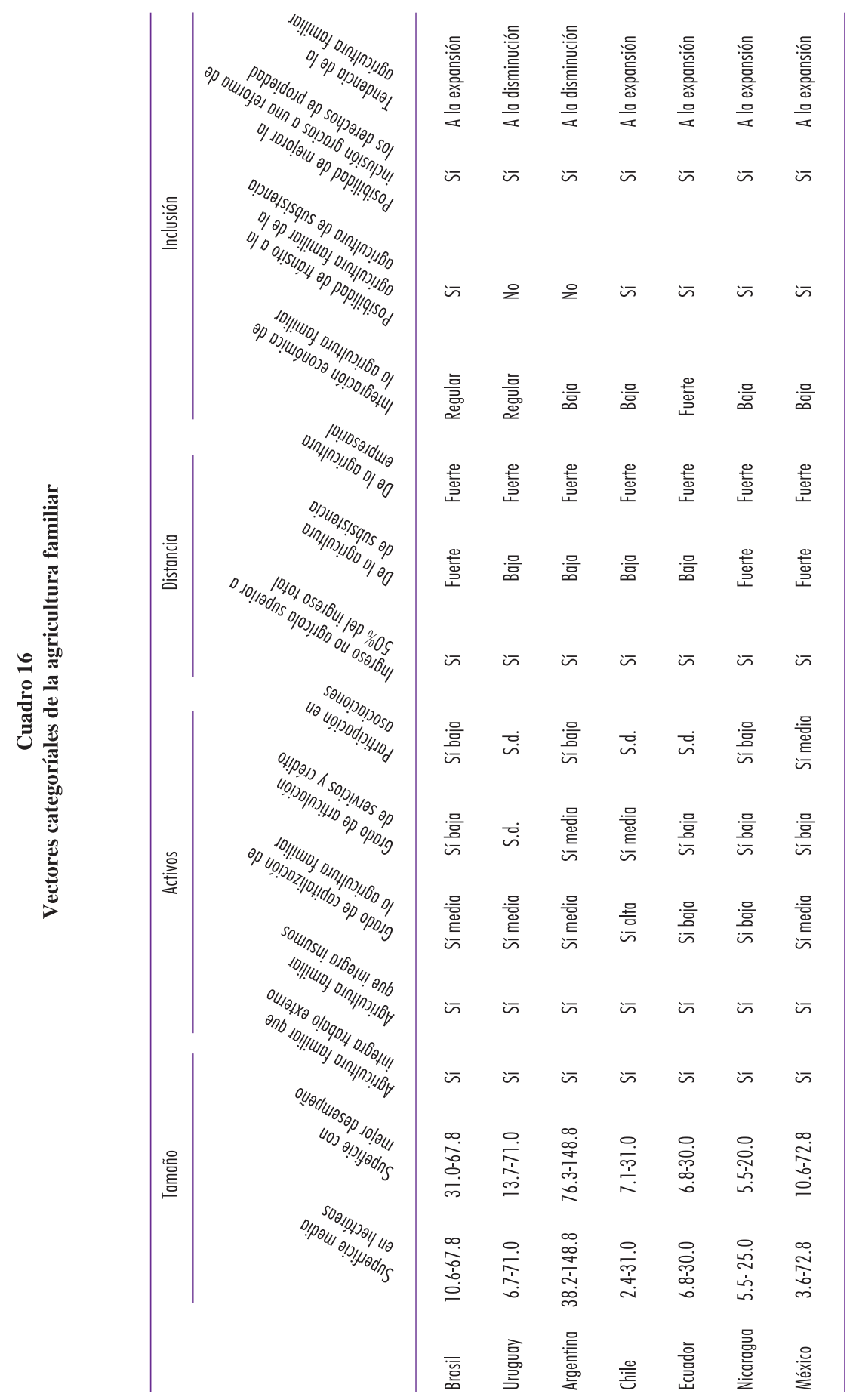


comunicación interpersonal Esto último afecta el acceso a los servicios públicos y privados. El resultado es que los efectos positivos del upstream linkage así como del downstream linkage no se distribuyen en modo uniforme al interior de la agricultura familiar.

A juzgar de la notable diferencia que se registra en el ingreso familiar, la agricultura familiar presenta — con la excepción de Uruguay y Argentina - una gran distancia respecto a la agricultura de subsistencia. El uso exclusivo del ingreso como indicador de magnitud de diferencia entre formas de agricultura impide conceder la debida importancia al conjunto de activos que obran en poder de los agricultores de subsistencia.

¿Es la diversidad en los activos lo que impide el paso de los agricultores de subsistencia a la agricultura familiar? Si los agricultores familiares se ven obstaculizados para tener acceso a los servicios públicos como a los activos intangibles, es decir, educación y organización en formas asociativas, a mayor razón lo son los agricultores de subsistencia. Ello significa que la verdadera y única diferencia entre la agricultura familiar y la agricultura de subsistencia reside en las barreras que obstaculizan la toma de decisiones y, por tanto, las estrategias de los agricultores de subsistencia.

El vector cualitativo nos dice que la agricultura familiar es una forma expansiva, con excepción de Uruguay y Argentina; en estos países se explican por el excesivo peso de la ganadería. Debemos preguntarnos si la capacidad de la agricultura familiar para incluir nuevos actores, provenientes de la agricultura de subsistencia y de los trabajadores rurales sin tierras, no depende de la existencia de instituciones formales e informales que bloquean su expansión. En particular, ¿los países disponen de un mercado de trabajo, de tierra y de capital capaz de sostener el proceso de expansión de la agricultura familiar mediante la absorción de los agricultores de subsistencia para así lograr reducir la pobreza rural?

La bibliografía sobre el mercado de tierras muestra que se caracteriza por un alto grado de imperfección con costos de transacción elevados; costos que favorecen más a los propietarios para los cuales la tierra es una renta, favorecida por el notable incremento que ha conocido el precio de la tierra desde 1980 (FAO 1994, FAO 1995). Vale la pena recordar que la reforma de la reforma agraria en México a partir de 1992 -que permitió la venta de tierras comunales y ejidales, bajo ciertas condicioneshizo posible la mercantilización de la tierra aunque no ha logrado regular el mercado de tierras (Concheiro, 1998).

En los últimos años se insiste que el escaso dinamismo en el mercado de arriendo de tierra bloquea el ascenso de muchos agricultores familiares y de subsistencia, 
especialmente en las familias más jóvenes, las que recién inician el ciclo de reproducción familiar. En Argentina y en México se aprecia el fenómeno, según el cual se arriendan tierras que se integran a la dotación de que se dispone para establecer una mejor relación con el trabajo familiar y no familiar disponible.

El acceso a la tierra vía arriendo o formas de colonato permitiría expandir la agricultura familiar (De Janvry, Macours y Sadoulet 2002). A diferencia de lo que acontece en otras áreas del mundo, el porcentaje de tierra arrendada es baja pues fluctúa entre $0.9 \%$ de la superficie total en Perú y $12.2 \%$ en Uruguay, aunque la norma es que supere 4\% de la superficie total (Díaz et al., 2002).

La informalidad y la breve duración de los contratos de arriendo y de colonato de la tierra, por lo general inferiores a un año, así como la segmentación del mercado de la tierra, originan incertidumbre en los derechos de propiedad, bloquea las mejoras que puedan realizar los arrendatarios y colonos debido al elevado riesgo de ser expulsados por los propietarios, como ha sucedido a lo largo de más de dos siglos (Reydon y Plata, 1998; Melmed-Sanjak, 1998).

Gordillo de Anda ha formulado algunas propuestas para generar un cambio que mejore el desempeño de la agricultura familiar y su capacidad expansiva (Gordillo de Anda 2004:76-78). Este autor plantea la necesidad de políticas públicas permanentes —es decir, no condicionadas por el periodo presidencial— de sostén al ingreso rural y de promoción de iniciativas entre los grupos rurales con el fin de asociarlos para sostener la continuidad de los programas de apoyo al ingreso rural. El ejercicio de los derechos ciudadanos da continuidad a las políticas públicas y reduce el sesgo asistencial y estatista presente en los programas de gobierno.

La agricultura familiar encuentra su fundamento en los activos tangibles e intangibles de que disponen en forma diferenciada los miembros del núcleo familiar. A partir de estos activos las decisiones familiares determinarán el mix más conveniente con el fin de satisfacer las necesidades de la reproducción del núcleo familiar y de promoción de sus integrantes por medio de la expansión del ingreso.

Un papel importante en las decisiones adoptadas para identificar el mix óptimo de los activos lo tienen los activos derivados de los derechos ciudadanos (la capacidad de votar y de ser elegido) gracias a los cuales se pueden expandir los activos específicamente familiares mediante la participación en los niveles de gobierno y en las organizaciones sociales (asociaciones, cooperativas, partidos políticos). La participación eleva la posibilidad de obtener, en reciprocidad de los impuestos que pagan, el acceso a los servicios públicos, lo cual reduce los costos de transacción que afectan la unidad productiva. 
Las decisiones familiares dan vida a estrategias a breve, medio y largo plazos, todas atribuibles a la racionalidad de la reproducción del grupo familiar y a la obtención del máximo de beneficio posibles en términos de ingresos para ser destinado al consumo y al ahorro para invertirlo en la expansión de la actividad productiva o en la diversificación de las actividades familiares fuera de la agricultura.

La agricultura familiar se desempeña en múltiples actividades procurando aumentar el trabajo familiar y no familiar disponible con el fin de reducir sus precarios activos en tierra y capital. Para ello desarrolla una estrategia que asegure 1) La mayor eficiencia en la relación trabajo y tierra, que logra mediante la ampliación de su parcela por medio del arriendo y el colonato; 2) La mayor eficiencia en la relación trabajo y capital se obtiene con integrar insumos autoproducidos e insumos de origen industrial, lo mismo ocurre con el acceso a los servicios públicos y privados. Esta estrategia proporciona mayor flexibilidad al integrar trabajo familiar y no familiar remunerado, al incrementar el trabajo y la dotación de tierra así como la relación trabajo, tierra y capital.

Con base en las estrategias aquí especificadas se puede afirmar que:

1. La agricultura familiar no está dominada sino tan sólo condicionada por la extensión de tierra.

2. Tiene la capacidad y los medios para diseñar diferentes formas para explotar la unidad.

3. Presenta la capacidad para integrar nuevos productores en la agricultura familiar, a condición de que los programas impulsen la flexibilidad en la relación trabajotierra y trabajo-capital y tengan un bajo contenido asistencialista.

4. La flexibilidad de los factores de producción caracteriza la agricultura familiar como una agricultura de mercado con objetivos similares a la agricultura empresarial. Por tanto, no hay un conflicto entre agricultura familiar y mercado puesto que la primera está inmersa en el segundo.

Su nexo con el mercado es el resultado de la constante reducción temporal y espacial entre las unidades productivas y los lugares de mercadeo por efecto de las innovaciones tecnológicas (caminos, comunicaciones, etcétera) y por efecto de la reducción que ocurre en los costos de transacción que disminuyen las asimetrías, sin hacerlas desaparecer.

Con el mercado de trabajo, la agricultura familiar interactúa cuando cede trabajo familiar y contrata mano de obra asalariada. Con el mercado de la tierra interactúa 
porque arrienda o adopta contratos de colonato. Con el mercado de capitales interactúa por medio de los servicios de la banca comercial y de fomento. Con el mercado de bienes interactúa porque incrementa la capacidad de ofrecer bienes a las industrias y al sector urbano y porque obtiene servicios de comercialización.

El resultado de estas estrategias fundadas en la interdependencia es visible en los ingresos que se organizan con base en el mismo principio de la integración, es decir, conjuntar los ingresos de los miembros de las familias derivados de las actividades agrícolas y de las actividades rurales y no rurales asalariadas, por cuenta propia y de la emigración, para definir el ingreso neto familiar.

En suma, la agricultura familiar es una agricultura compuesta de múltiples actividades de mercado dotada de gran dinamismo porque encuentra su fundamento en las decisiones que adoptan los integrantes de la familia. Estas decisiones ponen en juego, de forma interactiva, la totalidad de activos tangibles e intangibles y dan vida a estrategias a breve, medio y largo lapsos. El activo que moviliza las estrategias es el trabajo y se visualiza en las estrategias productivas y de mercado cuyo objetivo es garantizar la reproducción y expansión social de la familia y de sus relaciones con la localidad y el desarrollo territorial. 


\section{Bibliografía}

Barraclough, Solon y Collarte, Juan Carlos, $E l$ hombre y la tierra en América Latina. Resumen de los informes CIDA sobre tenencia de la tierra en Argentina, Brasil, Colombia, Chile, Ecuador, Guatemala, Perú, Santiago, Universitaria, 1972.

Berdegué, Julio A., Eduardo Ramírez, Thomas Reardon y Germán Escobal, "Empleo e ingresos rurales no agrícolas en Chile", en Empleo e ingresos rurales no agrícolas en América Latina, Santiago, CEPAL-FAORIMISP, 2004.

Carballido, Carlos, Articulación de los pequenos productores con el mercado: limitantes y propuestas para superarlas, Buenos Aires, Ministerio de Economía y Producción, Dirección de Desarrollo Agropecuario, 2004.

Carmagnani, Marcello, El otro occidente. América Latina desde la invasión europea a la globalización, México, FCE-COLMEX-Fideicomiso Historia de las Américas, 2004.

y Gustavo Gordillo de Anda (ed.), Desarrollo social y cambios productivos en el mundo rural europeo contemporáneo, México, FCE-COLMEX-Fideicomiso Historia de las Américas, 2000.

Chayanov, A. V., Peasant Farm Organization, 1925, Homewood, The American Economic Association, 1966.

CEPAL, Economía campesina y agricultura empresarial. Tipoología de productores del agro mexicano, México, Siglo XXI, 1982.

, Instituciones y pobreza rurales en México y Centroamerica, Santiago, CEPAL, 2001.

Coleman, J. S., "Social Capital in the Creation of Human Capital", American Journal of Sociology, núm. 94, 1998, pp. 95-120.

Concheiro, Luciano, "Les paysans méxicains face aux politiques de liberalisation des marchés de la terre", en Bay, Marguerite (ed.), Poliques neo-liberales et acteurs ruraux au Méxique, París, L'Harmattan, 1998.

Cord, Louise y Quentin Wodon, Do Mexico's Agricultural programs Alleviate Poverty? Evidence from the Ejido Sector, Washington, DC, Banco Mundial, 2001.

Corral, Leonardo y Thomas Readon, "Ingreso rural no agrícola en Nicaragua", en Empleo e ingresos rurales no agrícolas en América Latina, Santiago, CEPAL-FAO-RIMISP, 2004.
Da Silva, José Graziano y Mauro Eduardo del Grossi, "Empleo no agrícola e ingresos en las zonas rurales de Brasil: patrones y evolución", en Empleo e ingresos rurales no agrícolas en América Latina, Santiago, CEPAL-FAO-RIMISP, 2004.

y Antonio Carlos Laurenti, "La evolución de las actividades no agrícolas y las vinculaciones intersectoriales en Brasil", IE/Unicamp, núm. 75, 1999.

De Grammont, Hubert C., "Política Neoliberal, estructura productiva y organización social de los productores: una visión de conjunto", en Antonio Yúnez-Naudé (ed.), Los pequeños productores rurales en México, México, COLMEX, 2000.

De Janvry, Alain, The Agrarian Question and Reformism in Latin America, Baltimore, Johns Hopkins University Press, 1981.

y Peter Glikman, Encadenamientos de producción en la economía campesina en el Ecuador, San José, FIDA-IICA, 1991.

, Karen Macours y Elisabeth Sadoulet, "El acceso a tierras a través del arrendamiento", en El acceso a la tierra en la agenda de desarrrollo rural, Washington, DC, BID, 2002.

y Elisabeth Sadoulet, "Estrategias de ingreso de los hogares rurales de México: el papel de las actividades desarrolladas fuera del predio agrícola", en Empleo e ingresos rurales no agrícolas en América Latina, Santiago, CEPAL-FAO-RIMISP, 2004.

Del Grossi, Mario Edoardo y José Graziano da Silva, "El empleo en las familias agrícolas y rurales en Brasil 1992-1997", Estudos Sociedade e Agricultura, 1998, vol. 11, 1998, pp. 26-52.

Díaz, Manuel et al., Arrendamiento de tierras en América Latina: una alternativa de acceso a la tierra para pobres rurales, Santiago, FAO-RLC, 2002.

Dirven, Martine, "Rural non-farm employment and rural diversity in Latin America", CEPAL Review, núm. 83, agosto de 2004, pp. 47-64.

Echenique L., Jorge, "Mercado de tierras en Chile", en Reydon Baastian y Pedro Ramos, (ed.), Mercados y políticas de tierras (experiencias en la América Latina, Campinas, Universidade Estadual de Campinas, 1996. 
Elbers, Chris y Lanjouuw, "Transferencia intersectorial, crecimiento y desiguadad en Ecuador rural", en Empleo e ingresos rurales no agrícolas en América Latina, Santiago, CEPAL-FAO-RIMISP, 2000.

Ellis, Frank, Peasant Economies. Farm Households and Agrarian Development, Cambridge, Cambridge University Press, 1988.

FAO, El mercado de tierras en el Ecuador: estudio integrado de las regiones del litoral y de la sierra, Roma, FAO, 1995a.

FAO, El mercado de tierras en México, Roma, FAO, 1995b.

FAO, The State of Food and Agriculture, Roma, FAO, 1998.

FAO, Informe anual Nicaragua, Tegucigalpa, FAO, 2000.

Feder, Ernest, The Rape of Peasantry. Latin America's Landholding System, Garden City, Anchor Books, 1971.

Gordillo de Anda, Gustavo, "Food Security and Family Farming", CEPAL Review, núm. 83, agosto de 2004, pp. 67-79.

, Alain de Janvry y Elisabeth Sadoulet, La segunda reforma agraria de México: respuestas de familias y comunidades, 1990-1994, México, FCE-COLMEX-Fideicomiso Historia de las Américas, 1999.

Guanziroli, Carlos Enrique y Elizabeth de C. S. Cardim, Novo Retrato da Agricultura Familiar, Brasilia, INCRA-FAO, 2000.

Hernández, María Isabel, "Una tipología de los productores agropecuarios", en Antonio Yúnez-Naudé (ed.), Los pequeños productores rurales en México, México, COLMEX, 2000.

Jordán, Fausto, "Mercado de tierras en el Ecuador", en Reydon Baastian y Pedro Ramos (ed.), Mercados y políticas de tierras (experiencias en la América Latina), Campinas, Universidade Estadual de Campinas, 1996.

Lanjouw, Peter, "Rural non Agricultural Employment and Poverty in Ecuador", Economic Development and Cultural Change, 48, 1, 1999, pp. 91-122.

, La pobreza y la economía no agrícola en los ejidos de México: 1994-1997, Washington, DC, Banco Mundial, 2001.

Lattuada, Mario, El crecimiento económico y el desarrollo sustentable en los pequeños y medianos productores argentinos de fines del siglo $\mathrm{XX}$, Mendoza, $\mathrm{X}$ Jornadas de la Asociación Argentina de Extensión Rural, 2000 .

Vol. 39, núm. 153, abril-junio / 2008
Leite, Sergio, "Autoconsumo y sustentabilidad en la agricultura familiar: una aproximación a la experiencia brasileña", en Belik, Walter (ed.), Politicas de seguridad alimentaria y nutrición en Amedica Latina, São Paulo, Huicitec, 2004.

Llambi, Luis, "Emergence of Capitalized Family Farms in Latin America", Comparative Studies in Society and History, 31, 4, 1989, pp. 745-774.

Martínez V., Luciano, Actividades rurales no agrícolas en Ecuador, Santiago, FAO-RLC, 2000.

Melmed-Sanjak, Jolyne, "Mercados de tierras en América Latina", en Perspectivas sobre mercados de tierras rurales en América Latina, Washington, DC, 1998.

"Metodologia para caracterizacão do perfil da agricultura familiar e de seus principais sistemas de producão", 1999, www.incra. gov.br.

Milevic F., Ximena y Julio A. Berdegué, Empleo e ingreso en el sector campesino chileno, Santiago, RIMISP, 1998.

Mora, Jorge y José María Sumpsi, Desarrollo rural: nuevos enfoques y perspectivas, Santiago, FAO-FODEPAL, 2004.

Primi, A., The Costs of Distance: Rural Poverty Through a Territorial Perspective, Ph. D. Dissertation, Pavia, University of Pavia, 2002.

Rello, Fernando y Marcel Morales, The Rural Non-Farm Economy. Linkages and Employment in a Mexican Region, Roma, FAO, 1998.

Reydon, Baastian y Ludwig A. Plata, "Políticas de mercados de tierra en Brasil", en Perspectivas sobre mercados de tierra rurales en América Latina, Washington, DC, BID, 1998.

Ruerd, Ruben y Zvi Lerman, "Why Nicaraguan Peasant Stay in Agricultural Production Cooperatives", European Review of Latin American and Caribbean Studies, 78, 2005, pp. 31-47.

Schejtman, Alejandro, "Elementos para una teoría de la economía campesina: pequeños propietarios y campesinos de hacienda", $E l$ Trimestre Económico, núm. 166, 1975.

"Agroindustria y pequeña agricultura: experiencias y opciones de transformación", en CEPAL-FAO-GTZ, Agroindustria y pequeña agricultura: vínculos, potencialidades y oportunidades comerciales, Santiago, 1998.

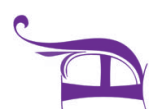


Simmons, Phil, Overview of Smallholders Contract Farming in Developing Countries, Armidale, University of New England, 2002.

Sola, Felipe, "Los tipos de empresas agropecuarias", en Barsky, D. (ed.), El desarrollo agropecuario pampeano, Buenos Aires, Grupo Editor Latinoamericano, 1991.

Solo de Zaldívar, Víctor, "Los paradigmas de la 'nueva ruralidad a debate': el proyecto de desarrollo de los pueblos indígenas y negros del Ecuador", Revista Europea de Estudios Latinoamericanos, núm. 79, abril de 2005, pp. 7-47.

Uruguay Agroalimentario 2002-2004, Montevideo, 2005

Tepicht, Jerzy, Marxisme et agriculture: le paysan polonais, París, Armand Colin, 1973.
Tort, María Isabel, Silvana Bearzotti y Guillermo Neiman, "Trabajo y producción en las explotaciones familiares", en Barsky, D. (ed.), El desarrollo agropecuario pampeano, Buenos Aires, Grupo Editor Latinoamericano, 1991.

Wilkinson, John, "La pequeña producción y su relación con sistemas de producción", en Belik, Walter (ed.), Politicas de seguridad alimentaria y nutrición en América Latina, São Paulo, Huicitec, 2004.

Yúnez Naudé, Antonio, J. Edward Taylor y Javier Becerril García, "Los pequeños productores rurales: características y análisis de impactos", en Antonio Yúnez-Naudé (ed.), Los pequeños productores rurales en México, México, COLMEX, 2000.

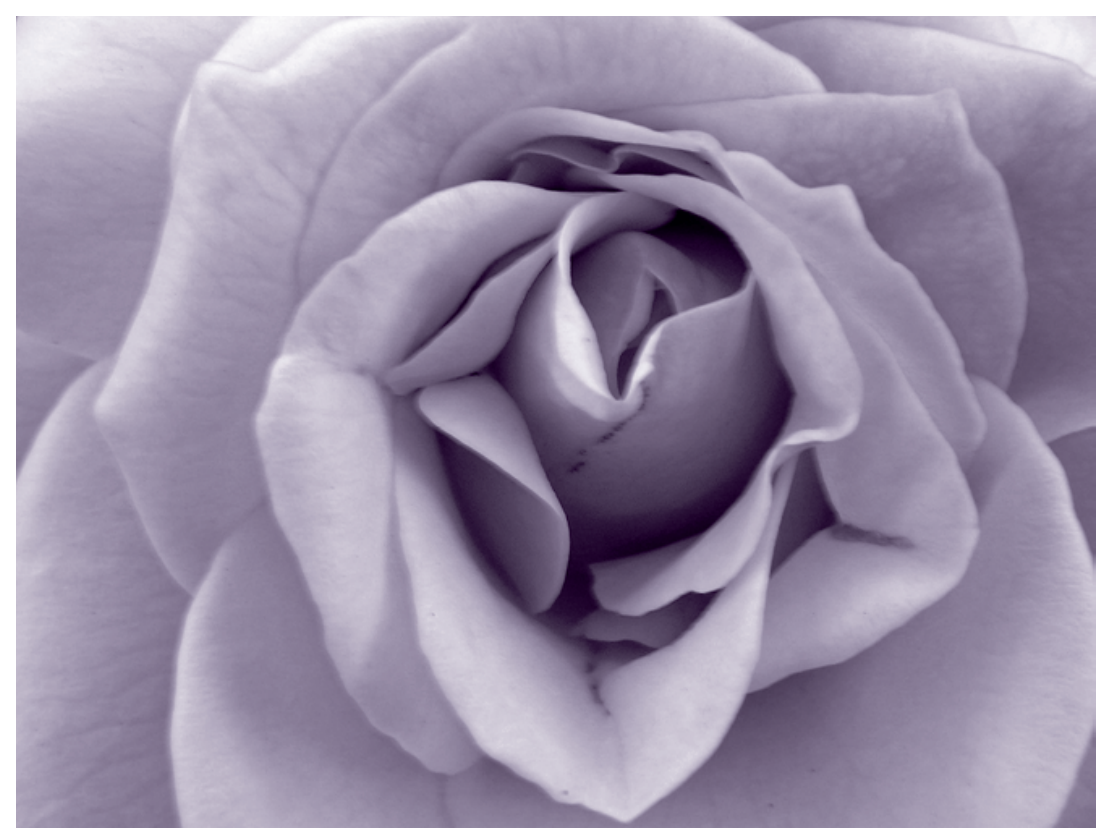

Buenos Aires, 2005. PAI 